\title{
Radiotherapy-induced plasticity of prostate cancer mobilizes stem-like non-adherent, Erk signaling-dependent cells
}

\author{
L Kyjacova ${ }^{1}$, S Hubackova ${ }^{1}$, K Krejcikova ${ }^{1}$, R Strauss ${ }^{2}$, H Hanzlikova ${ }^{1}$, R Dzijak ${ }^{1}$, T Imrichova ${ }^{1,2}$, J Simova ${ }^{3}$, M Reinis ${ }^{3}$, J Bartek ${ }^{k, 1,2}$ \\ and Z Hodny,
}

Fractionated ionizing radiation combined with surgery or hormone therapy represents the first-choice treatment for medium to high-risk localized prostate carcinoma. One of the main reasons for the failure of radiotherapy in prostate cancer is radioresistance and further dissemination of surviving cells. In this study, exposure of four metastasis-derived human prostate cancer cell lines (DU145, PC-3, LNCaP and 22RV1) to clinically relevant daily fractions of ionizing radiation (35 doses of 2 Gy) resulted in generation of two radiation-surviving populations: adherent senescent-like cells expressing common senescenceassociated markers and non-adherent anoikis-resistant stem cell-like cells with active Notch signaling and expression of stem cell markers CD133, Oct-4, Sox2 and Nanog. While a subset of the radiation-surviving adherent cells resumed proliferation shortly after completion of the irradiation regimen, the non-adherent cells started to proliferate only on their reattachment several weeks after the radiation-induced loss of adhesion. Like the parental non-irradiated cells, radiation-surviving re-adherent DU145 cells were tumorigenic in immunocompromised mice. The radiation-induced loss of adhesion was dependent on expression of Snail, as siRNA/shRNA-mediated knockdown of Snail prevented cell detachment. On the other hand, survival of the non-adherent cells required active Erk signaling, as chemical inhibition of Erk1/2 by a MEK-selective inhibitor or Erk1/2 knockdown resulted in anoikis-mediated death in the non-adherent cell fraction. Notably, whereas combined inhibition of Erk and PI3K-Akt signaling triggered cell death in the non-adherent cell fraction and blocked proliferation of the adherent population of the prostate cancer cells, such combined treatment had only marginal if any impact on growth of control normal human diploid cells. These results contribute to better understanding of radiation-induced stress response and heterogeneity of human metastatic prostate cancer cells, document treatment-induced plasticity and phenotypically distinct cell subsets, and suggest the way to exploit their differential sensitivity to radiosensitizing drugs in overcoming radioresistance.

Cell Death and Differentiation (2015) 22, 898-911; doi:10.1038/cdd.2014.97; published online 11 July 2014

Prostate carcinoma $(\mathrm{CaP})$ is the most frequent type of cancer in men, and the sixth cause of cancer-associated death in men worldwide. ${ }^{1}$ Despite the advances in diagnosis and therapy of $\mathrm{CaP}$, the mortality has remained almost unchanged for the last decades. Currently, the most successful treatment for localized $\mathrm{CaP}$ is prostatectomy with postoperative fractionated radiotherapy, significantly improving metastasis-free and overall survival, where the median of a 15-year survival is around $47 \%$ of patients. ${ }^{2,3}$ The rest of the patients develop a metastatic disease that is incurable due to the resistance of $\mathrm{CaP}$ to androgen ablation, radiotherapy and chemotherapy. Therefore, understanding the mechanisms of radioresistance and chemoresistance of primary and metastatic CaP, respectively, is fundamental for future efforts to develop more efficient therapeutic strategies.

The mechanism of radioresistance of $\mathrm{CaP}$ is not entirely clear. Downregulation of some proteins, such as DAB2IP in metastatic prostate cancer, results in radioresistance and was

\footnotetext{
${ }^{1}$ Department of Genome Integrity, Institute of Molecular Genetics, v.v.i., Academy of Sciences of the Czech Republic, Prague, Czech Republic; ${ }^{2}$ Genome Integrity Unit, Danish Cancer Society Research Center, Copenhagen, Denmark and ${ }^{3}$ Department of Tumour Immunology, Institute of Molecular Genetics, v.v.i., Academy of Sciences of the Czech Republic, Prague, Czech Republic

*Corresponding authors: J Bartek and Z Hodny, Department of Genome Integrity, Institute of Molecular Genetics ASCR, v.v.i., Academy of Sciences of the Czech Republic, Videnska 1083 CZ 142 20, Prague 4, Czech Republic. Tel: + (420) 24106 3151; Fax: + (420) 24106 2289; E-mail: jb @ cancer.dk or hodny@img.cas.cz Abbreviations: Akt (PKB), protein kinase B; 53BP1, p53 binding protein 1; AKTi, Akt inhibitor; APC, allophycocyanin; Bcl-XL, BCL-2-like 1, long isoform; Bim (EL), Bcl-2 interacting mediator of cell death, extra large form; BrdU, 5-bromo-2'-deoxyuridine; CaP, prostate carcinoma; DAPI, 4',6-diamidino-2-phenylindole; DLL1, delta-like 1; DLL4, delta-like 4; DNA, deoxyribonucleic acid; Dox, doxycycline; Doxo, doxorubicine; ECM, extracellular matrix; EdU, 5-ethynyl-2'-deoxyuridine; EGF, epidermal growth factor; EMT, epithelial-to-mesenchymal transition; ERK1 (MAPK3), mitogen-activated protein kinase 3; ERK2 (MAPK1), mitogen-activated protein kinase 1; ERKi, Erk inhibitor; FACS, fluorescence-activated cell sorting; FAK, focal adhesion kinase; FGF, fibroblast growth factors; flR, fractionated irradiation; fRT, fractionated radiotherapy; GAPDH, glyceraldehyde 3-phosphate dehydrogenase; Gy, gray; H2AX, H2A histone family, member X; Hes1, hairy and enhancer-of-split 1; Hey1, hairy/ enhancer-of-split related with YRPW motif 1; HTS, high throughput sampler; IL, interleukin; IR, irradiation; ITGA2, integrin, alpha 2; LAMC2, laminin, gamma 2; LAMA3, laminin, alpha 3; MACS, magnetic-activated cell sorting; MET, mesenchymal-epithelial transition; MMP-7, matrix metallopeptidase 7; NFkappaB, nuclear factor kappa B; Oct-4, octamer-binding transcription factor-4; PI3K, phosphoinositide-3-kinase; PMA, phorbol 12-myristate 13-acetate; PML, promyelocytic leukemia protein; PML NBs, promyelocytic leukemia nuclear bodies; qRT-PCR, quantitative real time polymerase chain reaction; RNA, ribonucleic acid; RPL37a, ribosomal protein L37a; S.D., standard deviation; SA- $\beta$-gal, senescence-associated beta-galactosidase; siNT, Non-targeting siRNA; STAT, signal transducers and activators of transcription; CTCs, circulating tumor cells; Twist1, Twist-related protein 1
}

Received 14.12.13; revised 07.5.14; accepted 03.6.14; Edited by G Melino; published online 11.7.14 
proposed as a predictive marker of aggressive $\mathrm{CaP}$ The radioresistance in DAB2IP-deficient $\mathrm{CaP}$ cells reflects faster repair of DNA double-strand breaks, combined with decreased expression of proapoptotic caspases and enhanced levels of anti-apoptotic proteins Bcl-2 and STAT3. ${ }^{4}$ IL-6/STAT3 signaling plays an important role in radioresistance of $\mathrm{CaP}$ cells $\mathrm{s}^{5,6}$ and malignant properties in general. ${ }^{7}$ Inhibition of the PI3K-Akt pathway, together with the MAPK-Erk pathway, sensitizes CaP cells to IR, likely due to suppression of $\mathrm{AP}-1^{8}$ and NFkappaB ${ }^{9}$ transcription factors. Radiation-surviving $\mathrm{CaP}$ cells exhibit enhanced migration, higher levels of androgen and EGF receptors and activation of their downstream pathways, Ras-MAPK, PI3K-Akt and Jak-STAT. ${ }^{5}$ Thus the inhibition of IL- 6 signaling, which is highly activated in metastatic $\mathrm{CaP}$ cells, ${ }^{10,11}$ results in radiosensitization, ${ }^{6}$ inhibition of cell growth, invasion ${ }^{12-15}$ and angiogenesis. ${ }^{16}$

The clinical significance of this topic, and the intriguing yet fragmented insights into the cellular and molecular basis of $\mathrm{CaP}$ radioresistance, including its reportedly 'heritable' nature ${ }^{5}$ and the lack of a model of metastatic human CaP that would recapitulate the clinically relevant scenario of long-term fractionated radiotherapy, led us to perform the present study. To our knowledge, this is the first study of a series of human metastatic $\mathrm{CaP}$ cell lines in terms of their response to longterm fractionated irradiation ( $\mathrm{flR}, 35$ cycles of $2 \mathrm{~Gy}$, mimicking the clinical regimen), in a multifaceted biological and molecular analysis of the resulting $\mathrm{CaP}$ cell populations of both adherent and non-adherent nature. The present data set documents several novel findings including biological heterogeneity of the radiation-surviving cell subpopulations, their phenotypic plasticity, stem-like cell and tumorigenic properties. Furthermore, our results reveal differential sensitivity of the two major subpopulations of the radiation-surviving $\mathrm{CaP}$ cells to inhibition of complementary signaling cascades, suggesting a strategy for overall elimination of both subsets of metastatic human radiation-surviving CaP cells by combined targeting of their respective pro-survival signaling pathways.

\section{Results}

Fractionated ionizing radiation of CaP cells induces two prevalent phenotypes: senescent adherent cells and anoikis-resistant non-adherent cells. To elucidate radioresistance of metastatic CaP cells, we first followed the clinically used radiotherapy regimen ${ }^{2,3}$ and exposed four human $\mathrm{CaP}$ cell lines of metastatic origin (DU145, PC-3, LNCaP and 22RV1) to cumulative doses of $70 \mathrm{~Gy}$ (2 Gy applied every $24 \mathrm{~h}$ for 35 days). Characteristic phenotypic changes observed during the fIR course are schematically depicted in Figure 1a and shown in Figure 1b. As early as after the third dose of fIR, a continuing loss of adhesion was observed in all four cell lines, such non-adherent cells were able to reattach within 10-21 days after the last irradiation time point (re-adherent cells). However, on 35 doses of irradiation, a small subset of the initial cell population remained vitally attached (adherent cells). Similar loss of cell adhesion and subsequent re-adhesion was reproduced with irradiation regimens consisting of either ten consecutive doses of $2 \mathrm{~Gy}$ or one dose of $10 \mathrm{~Gy}$. Therefore, in some experiments, these shortened irradiation regimens were used.

Next, we characterized the radiation-surviving adherent fraction. Cell proliferation in this fraction was largely unaffected until the 10th dose of radiation, as detected by EdU incorporation in DU145 (39.1\% \pm 11.7 labeled, compared with $29.5 \% \pm 5.5$ control cells) and PC-3 (36.0\% \pm 10.6 labeled, compared with $22.5 \% \pm 5.9$ control cells), while the proliferation became slower between doses 11-15 (Supplementary Figure 1a). Among these adherent DU145 and PC-3 cells, some developed senescence-like morphology. The senescence was progressively developing during the course of irradiation (active DNA damage signaling was assayed as phosphorylation of Chk2 and p53, elevated expression of the

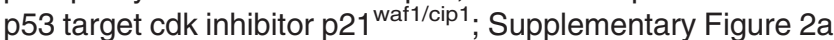
and foci positive for 53BP1 and phosphorylated histone H2AX; Supplementary Figure 2c) with characteristic cell enlargement, spreading and vacuolization (Figure 1b), nuclear aberrations, abundant chromatin bridges (Supplementary Figures $1 \mathrm{~b}$ and $\mathrm{c}$ ), positivity for senescenceassociated $\beta$-galactosidase (SA- $\beta$-gal) (Supplementary Figure 1d), and an increase of PML NBs (Supplementary Figure 2b). Notably, senescent DU145 cells pulsed with BrdU showed asynchronous labeling of nuclei (Supplementary Figure 1c) indicating ongoing DNA endoreduplication in adherent survivors. Some cells resumed proliferation $\sim 2$ weeks after the end of irradiation (Figures $1 \mathrm{~b}$ and $\mathrm{c}$ and Figure 4)

As indicated above, small subsets of surviving non-adherent cells were resistant to anoikis, and resumed adherent growth (Figures 1b and c; Supplementary Figure 1e). Once initiated, such re-adhesion was a sudden process lasting several days and encompassed the majority of non-adherent cells, many of them utilizing the already attached cells as adhesion substrate (Figure 1c; Supplementary Figures $1 \mathrm{f}$ and 2d). Formation of rosette-like membrane blebbing accompanied reattachment (Supplementary Figure 2d), as did sphere-forming growth (Figure 1c). The tumorigenicity of the re-adherent DU145 cells in immunodeficient mice was preserved (Supplementary Figure $2 \mathrm{e}$ ). The same effect of fIR was reproduced in the human breast cancer cell line MCF-7 (Supplementary Figures 1e, $f$ and $g$ ) indicating the phenomenon is not restricted to CaP cells only.

Altogether, fIR of tumor cells led to development of two phenotypically distinct: adherent and non-adherent radiation-surviving cell populations, both capable of renewed proliferation after termination of the radiation stress.

lonizing radiation induces expression of Snail and loss of cellular adhesion. As the loss of adhesion and resistance to anoikis indicated phenotypic changes, we compared both the non-adherent and adherent radiation-surviving $\mathrm{CaP}$ cells for factors involved in epithelial-mesenchymal transition (EMT). We analyzed mRNA levels for EMT-inducers Snail, Slug, Twist1, Twist2, Zeb1 and Zeb2 during flR in all four populations: parental $=$ non-irradiated, irradiated adherent, non-adherent and re-adherent. The transcription factors whose mRNA levels were altered, that is, Snail, Slug, Twist1 and Zeb2 are shown (Figure 2a; Supplementary Figure 3a). 
a fIR

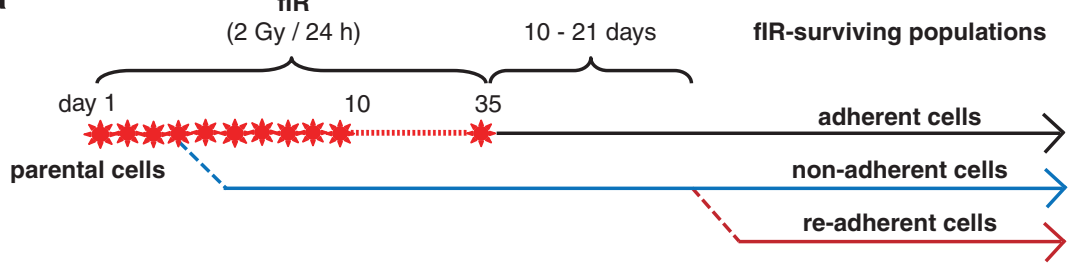

b

b ctrl
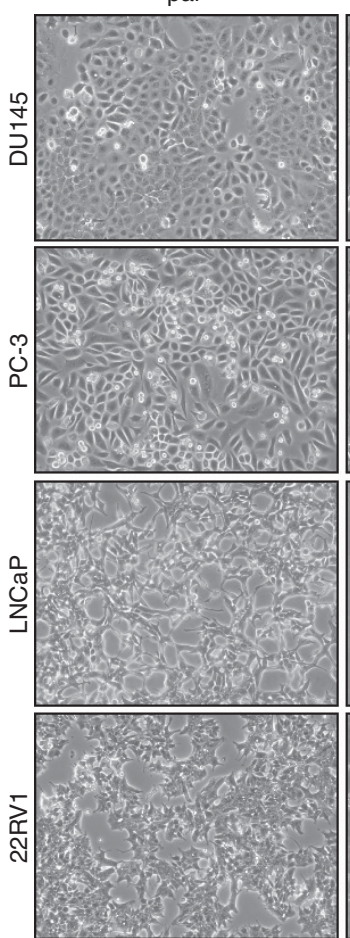

C
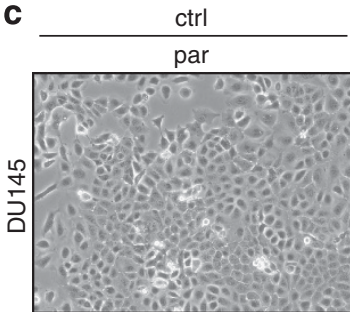

\begin{tabular}{ccc}
$35 \times 2$ Gy & \\
\hline adh non-adh & re-adh (32 d after last dose)
\end{tabular}
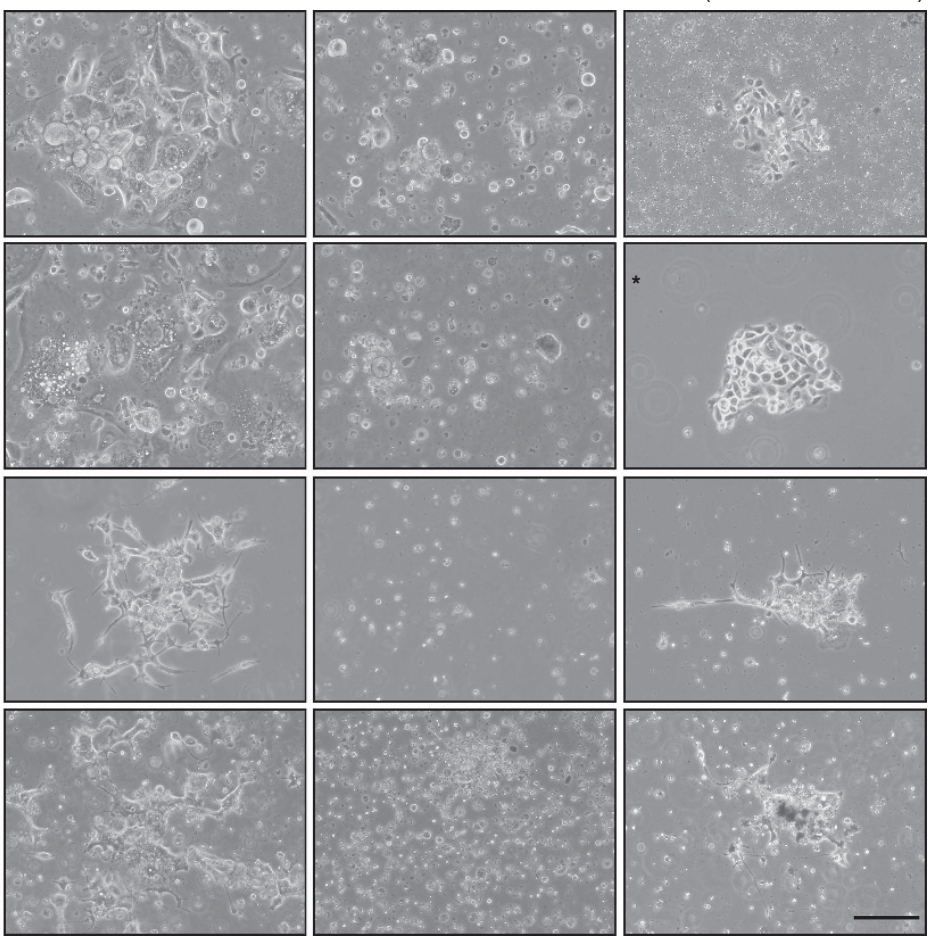

$35 \times 2$ Gy

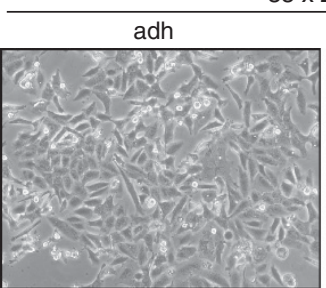

$25 \mathrm{~d}$ after last dose

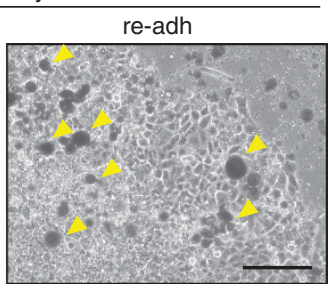

$32 \mathrm{~d}$ after last dose

Figure 1 Generation of adherent and non-adherent radiation-surviving populations in human prostate carcinoma cells by fIR. (a) Schematic representation of the irradiation protocol using $2 \mathrm{~Gy}$ every $24 \mathrm{~h}$ resulting in the generation of radiation-surviving populations (adherent, non-adherent and re-adherent) in human prostate cancer cell lines DU145, PC-3, LNCaP and 22RV1 (See Material and Methods for details). (b) Phase contrast microscopic images of non-irradiated parental cells (par) and fIR-surviving DU145, PC-3, LNCaP and 22RV1 cell populations after $35 \times 2$ Gy fIR (adh and non-adh) or 32 days after last dose of flR (re-adh). Representative phase contrast images of one from three independent experiments are shown. The image with asterisk represents the re-adherent colony of PC-3 cells obtained after 10 days of fIR. Scale bar, $100 \mu \mathrm{m}$. (c) Phase contrast images of control (parental) and irradiated adherent and re-adherent DU145 single-cell colonies captured at indicated time points after $35 \times 2$ Gy of flR. Note, the 'black' cells (arrowheads) are non-adherent cells starting to attach to the layer of adherent cells. Scale bar, $100 \mu \mathrm{m}$. adh, adherent; non-adh, non-adherent; par, parental; readh, re-adherent

The most consistent changes were observed for Snail, known to regulate stress resistance, stem cell-like commitment and EMT in various cancer types. ${ }^{17}$ Snail was induced by all three irradiation regimens in the non-adherent cells in both DU145 and PC-3 cells compared with parental and irradiated adherent cells at mRNA (Figure 2a,
Supplementary Figure $3 b$ ) and protein (Figures $2 b$ and $c$ ) levels (for basal expression of Twist1 in DU145 and PC-3, see Supplementary Figure 3c). Analogous Snail induction was observed in MCF-7 exposed to $10 \times 2$ Gy (Figures 2a and $b$ ). To test whether the loss of cell adhesion depends on Snail or Twist1, siRNA-mediated knockdown of either factor 


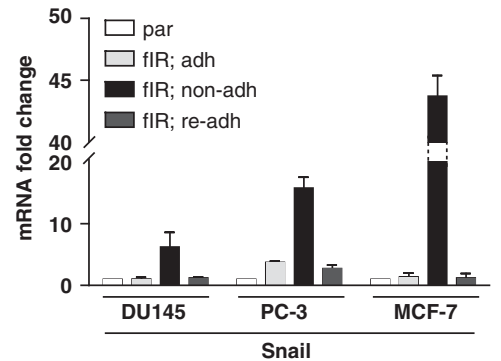

C

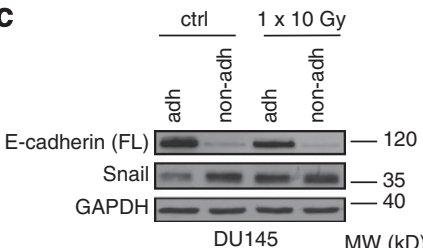

d
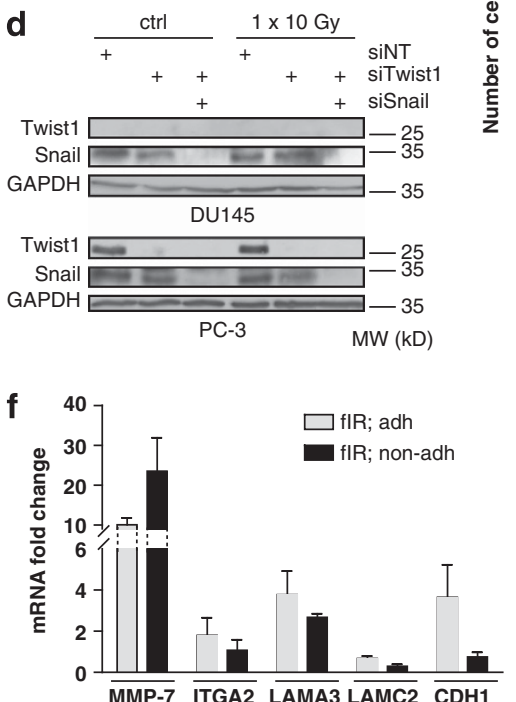

e b

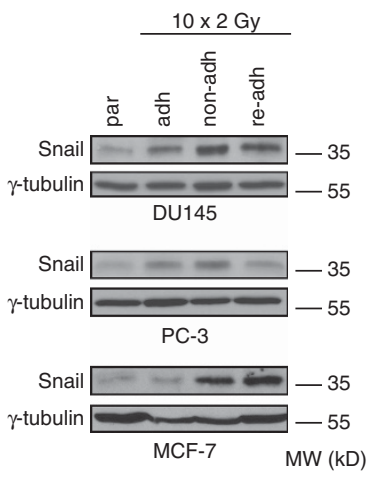

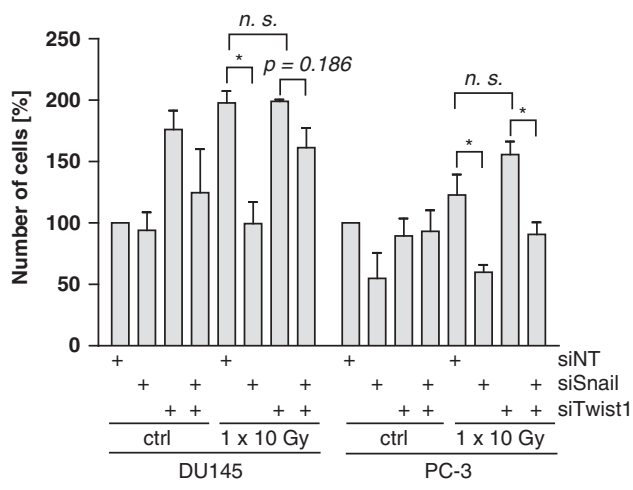

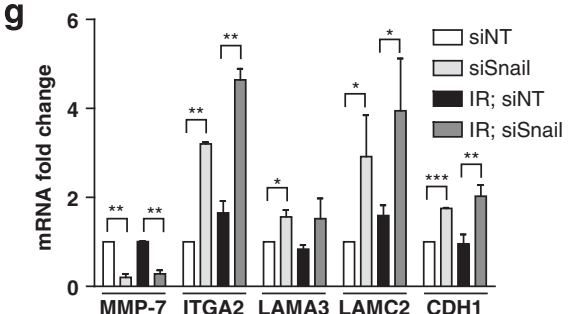

Figure 2 Snail expression in fIR-surviving human cancer cells. Real time qRT-PCR quantification of Snail mRNA levels (a) and Snail immunoblotting detection (b) in DU145, PC-3 and MCF-7 control (parental) or irradiated ( $10 \times 2$ Gy) adherent, non-adherent and re-adherent cell populations. RPL37a (DU145 and PC-3) and GAPDH (MCF-7) were used as reference genes in (a); gamma-tubulin was used as a loading control in b. (c) E-cadherin and Snail immunoblotting detection in adherent and non-adherent control and irradiated $(1 \times 10$ Gy) DU145 cells. GAPDH was used as a loading control. (d) Efficiency of siRNA-mediated knockdown of Snail (siSnail) and Twist1 (siTwist1) estimated by immunoblotting detection of Snail and Twist 1 in control or irradiated ( $1 \times 10$ Gy) DU145 and PC-3 cells. GAPDH was used as a loading control. (e) Effect of siRNA knockdown of Snail (siSnail) and Twist1 (siTwist1) on loss of adhesion expressed as relative number of detached cells assessed by FACS in control or irradiated ( $1 \times 10$ Gy) non-adherent DU145 and PC-3 cells. Non-targeting siRNA (siNT) was used as a negative control. Cells were irradiated $24 \mathrm{~h}$ after transfection and FACS-analyzed $48 \mathrm{~h}$ after IR. Non-irradiated cells transfected with non-targeting siRNA were set as $100 \%$ in both cell lines. (f) Real time qRT-PCR quantification of mRNA levels of Snail-regulated genes MMP-7, ITGA2, LAMA3, LAMC2 and CDH1 (E-cadherin) in radiation-surviving adherent and non-adherent DU145 cells after irradiation $(10 \times 2$ Gy). $\beta$-actin was used as a reference gene. (g) Effect of siRNA knockdown of Snail (siSnail) on Snail-activated (MMP-7) or -repressed genes (ITGA2, LAMA3, LAMC2 and $\mathrm{CDH} 1$ ) estimated by real time $\mathrm{qRT}-\mathrm{PCR}$ in control and irradiated $(1 \times 10 \mathrm{~Gy}) \mathrm{DU} 145$ cells. $\beta$-actin was used as a reference gene. Panels concerning real time $\mathrm{qRT}-\mathrm{PCR}$ represent data from at least two (f, $\mathbf{g}$ ) or three (a) independent experiments executed in triplicates. (e) Represents three independent experiments. Data in $\mathbf{a}, \mathbf{e}, \mathbf{f}, \mathbf{g}$ represent means \pm S.D. ${ }^{*} P<0.05 ;{ }^{* *} P<0.01 ;{ }^{* * *} P<0.001$

was performed in DU145 and PC-3 cells before a single dose of irradiation (10 Gy; Figure 2d). Knockdown of Snail, but not of Twist1, reverted the enhanced loss of adhesion in irradiated cells, while having no effect on control cells (Figure 2e). A similar suppressive impact of Snail downregulation on loss of adhesion was obtained using a tetracycline-inducible Snail shRNA system in DU145 cells exposed to $10 \times 2$ Gy fIR (Figures $3 d$ and e).

Furthermore, genes known to be positively regulated by Snail, such as MMP-7, ${ }^{18}$ or negatively, for example, integrin alpha2 (ITGA2 ${ }^{19}$ ), laminin alpha3 (LAMA3), laminin gamma2 $\left(\right.$ LAMC2 $\left.^{20}\right)$ and $\mathrm{E}$-cadherin $\left(\mathrm{CDH}_{1}{ }^{21,22}\right)$ were consistently altered in irradiated non-adherent DU145 cells (Figure 2f), indicating Snail activity. Indeed, knockdown of Snail led to decreased MMP-7 and increased ITGA2, LAMA3, LAMC2 and E-cadherin (Figure 2g). Furthermore, ITGA2 was elevated in the non-adherent DU145 cells with doxycyclineinducible Snail shRNA, consistent with Snail-mediated repression of this gene (Supplementary Figure $3 f$ ). Importantly, the major epithelial adhesion molecule E-cadherin was 

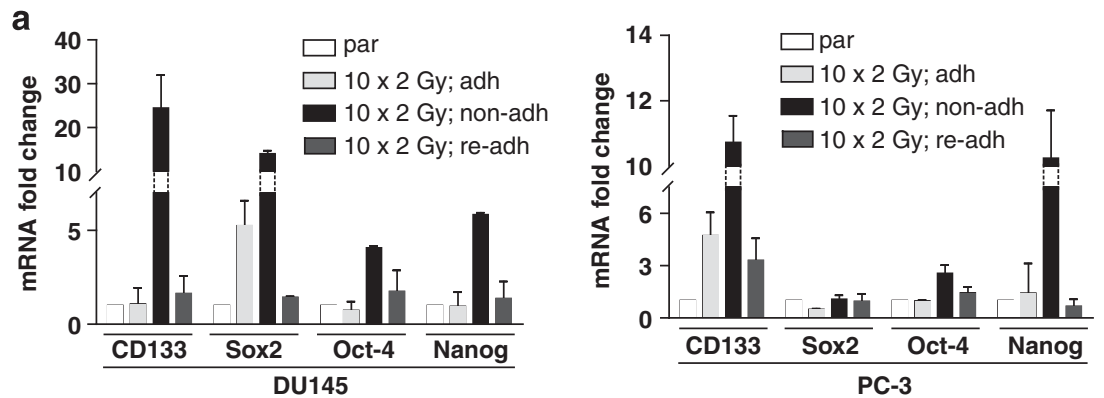

b
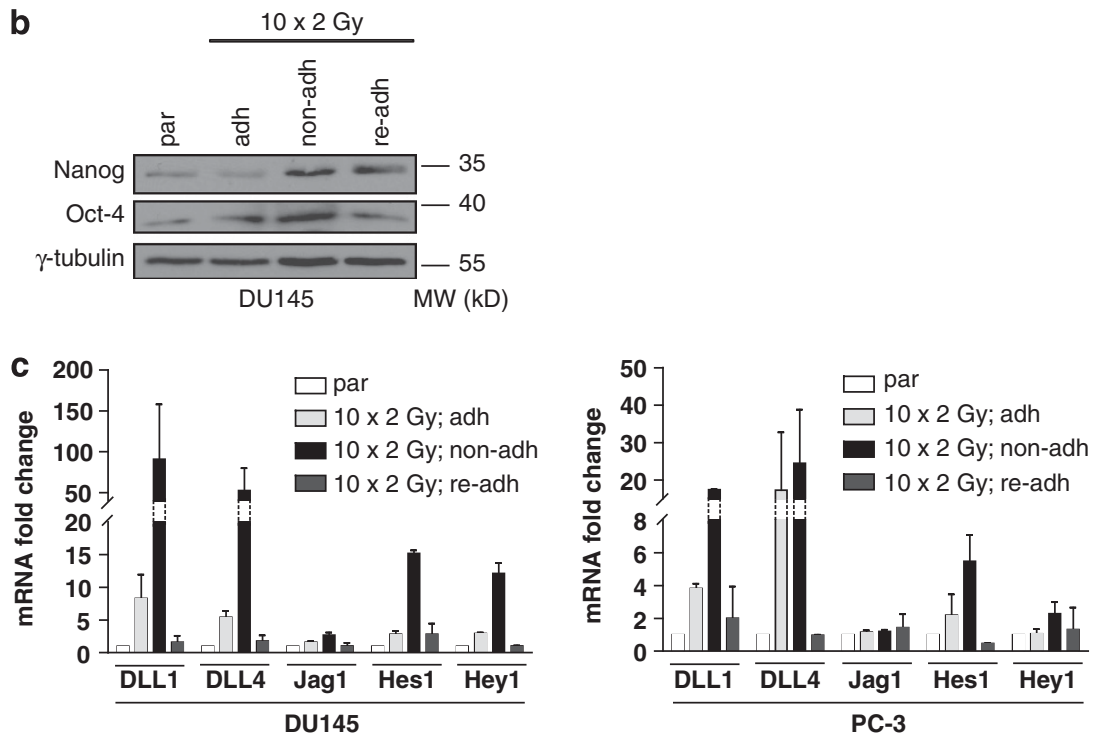

Figure 3 Non-adherent cells express stem cell-like markers. (a) Real time qRT-PCR detection of CD133, Sox2, Oct-4 and Nanog in control (parental) and irradiated $(10 \times 2$ Gy) radiation-surviving DU145 (left) and PC-3 (right) adherent, non-adherent and re-adherent cell populations. RPL37a was used as a reference gene. (b) Immunoblotting detection of Nanog and Oct-4 in control (parental) and irradiated (10 $\times 2$ Gy) adherent, non-adherent and re-adherent DU145 cells. Gamma-tubulin was used as a loading control. (c) Real time qRT-PCR quantification of Notch signaling ligands DLL1, DLL4, Jag1 and Notch signaling target genes Hes1 and Hey1 by real time qRT-PCR in control (parental) and irradiated (10 $\times 2$ Gy) DU145 (left) and PC-3 (right) radiation-surviving adherent, non-adherent and re-adherent cell populations. RPL37a was used as a reference gene. Data in all graphs represent means \pm S.D. from two independent experiments performed in triplicates

markedly decreased in non-adherent fractions of both irradiated and control cells (Figure 2c), confirming that EMT events accompanied the loss of cellular adhesion.

Overall, non-adherent CaP cells lose adhesive properties via EMT, and this process is amplified on radiation stress through elevated expression of Snail.

\section{Fractionated irradiation-induced expression of stem cell} markers in the non-adherent cells. The anoikis-resistant survival of non-adherent $\mathrm{CaP}$ cells might be associated with acquisition of stem cell properties induced during ionizing radiation. Indeed, compared with all other fractions of control and irradiated cells, the non-adherent DU145 and PC-3 cells showed higher mRNA levels of stem cell-associated genes CD133, Sox2, Oct-4 and Nanog (Figure 3a, Supplementary Figure $3 \mathrm{~g}$ ). Shortly after cell re-adhesion, these transcripts returned almost to the pre-irradiation levels observed in the parental cells, indicating a transiently mobilized stem-like cell stage during the non-adherent phase. The elevation of Nanog and Oct-4 protein levels was confirmed (Figure $3 b$ ). Notably, an increased activity of Notch signaling, characteristic for progenitor cells ${ }^{23,24}$ was detected as elevated mRNA of the NOTCH pathway-regulated genes $\mathrm{Hes}^{25}$ and $\mathrm{Hey} 1^{26}$ in the non-adherent irradiated fractions of both DU145 and PC-3 cells (Figure 3c). The induction of Hes1 and Hey1 transcription factors was accompanied by elevated NOTCH ligands DLL1 and DLL4 in irradiated cells (Figure 3c; Supplementary Figure 3h). The transcripts of DLL1, DLL4, Hes 1 and Hey1 in irradiated cells reverted nearly to parental cell levels after cell re-adhesion (Figure $3 c$ ).

Altogether, the non-adherent irradiated cells differ from the adherent irradiated cells by expression of stem-like cell markers and progenitor cell-associated Notch signaling, in a transient manner that reverted on cell re-adhesion.

Irradiated non-adherent cells do not proliferate. To assess proliferation of the radiation-surviving non-adherent cells, we labeled cells with the cell proliferation dye. Whereas the non-irradiated non-adherent cells re-adhered rapidly, during $24 \mathrm{~h}$, and on re-adhesion diluted the dye almost completely within 28 days consistent with ongoing cell proliferation, the non-adherent irradiated cells retained almost the same eFluor670 fluorescence intensity for the 28-day period (Supplementary Figures $4 a$ and b), indicating 
lack of cell proliferation. This was confirmed by very low level of EdU incorporation after a 3-hour pulse of EdU among the non-adherent cells (less than $2 \%$ EdU-positive cells at day 3 after the end of fIR), suggesting very low replicative activity (Figure 4). However, considering the non-adherent irradiated cells restarted proliferation shortly after re-adhesion, the non-adherent fIR survivors represented a pool of transiently non-proliferating cells capable of proliferation after reestablishment of the adherent phenotype.

Inhibition of Erk1/2 suppresses Snail expression and impairs survival of non-adherent cells. Snail levels are regulated by the Erk1/2 and PI3K/Akt pathways. ${ }^{27,28}$ Indeed, both Akt and Erk1/2 activities were highest between the second and third dose of IR (Figure 5a), coinciding with the highest levels of Snail and preceding the loss of cell adhesion. The ensuing loss of cell adhesion correlated with loss of active Akt and partial loss of Erk1/2 activity (Figure 5b). Consistent with a previous report, ${ }^{27}$ inhibition of Erk1/2 with the MEK-Erk inhibitor U0126 (ERKi) suppressed the levels of Snail in the adherent fraction (Figure 5c), while treatment of the non-adherent cells with

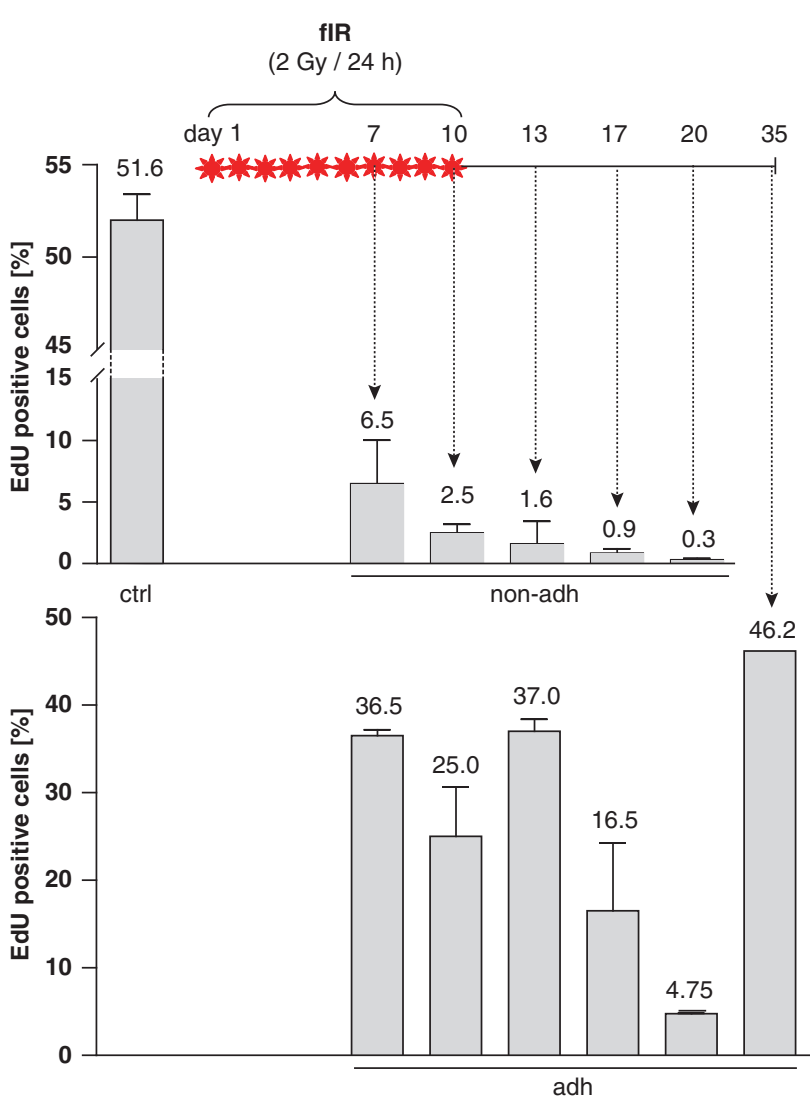

Figure 4 Proliferation of fIR-surviving adherent and non-adherent DU145 cells. Flow cytometry analysis of EdU incorporation using Click-iT EdU proliferation assay in irradiated $(10 \times 2$ Gy) non-adherent and adherent DU145 cells, during and after $f I R$, expressed as EdU-positive cells (from viable fraction in percentage, numbers above bars) of total cells analyzed. Non-irradiated adherent cells were used as a control (ctrl). Data (except adherent cells collected at day 35) represent means \pm S.D. from two independent experiments the ERKi resulted in anoikis, and also prevented cell detachment after a single dose of IR (Figure 5d; Supplementary Figure $5 \mathrm{a}$ ). Consistently, activation of the Erk1/2 pathway by a mixture of FGF and EGF (Supplementary Figure $5 \mathrm{~b}$ ) resulted in increased total numbers of detached cells (the sum of live and dead cells; Supplementary Figure 5c) and more surviving non-adherent cells among both the control and irradiated DU145 cells (Figure 5e). Excluding potential nonspecific effects of the ERKi, siRNA-mediated knockdown of Erk1 and/or Erk2 (Supplementary Figure 5e) impaired the loss of adhesion (Supplementary Figure 5d) and survival (Figure 5f) among non-adherent control as well as irradiated DU145 cells, thereby supporting the role of Erk $1 / 2$ signaling in the emerging anoikis-resistant cell survival after irradiation.

Anoikis is Bim-mediated apoptosis, ${ }^{29}$ and the level (and activity) of proapoptotic Bim is regulated by Erk1/2. ${ }^{29-31}$ Consistent with resistance to anoikis, the level of Bim in irradiated non-adherent DU145 cells was substantially lower than in the irradiated adherent cells (Supplementary Figure 5f). Inhibition of Erk1/2 led to increased levels of Bim both in control and irradiated cells (Figure $5 \mathrm{~g}$ ). Furthermore, activation of Erk1/2 by PMA had the opposite effect (not shown) implicating Erk-dependent ubiquitylation and degradation of Bim. ${ }^{32}$ In contrast, the anti-apoptotic factor $\mathrm{Bcl}-\mathrm{XL}$ was increased in non-adherent cells after irradiation (Supplementary Figure 5f). Inhibition of Erk1/2 led to a decrease of $\mathrm{Bcl}-\mathrm{XL}$ (Figure $5 \mathrm{~g}$ ) indicating $\mathrm{Bcl}-\mathrm{XL}$ is controlled by Erk1/2. Ectopic expression of Bcl-XL in DU145 cells (Figure $5 \mathrm{~h}$ ) resulted in significantly increased survival of the non-adherent cells after fIR, whereas inhibition of Erk $1 / 2$ suppressed survival among the Bcl-XL-overexpressing cells (Figure 5i), supporting the role of the Erk1/2-Bcl-XL axis in radiation-induced anoikis resistance.

In conclusion, loss of cell adhesion, Snail expression, levels of the apoptotic modulators Bim and $\mathrm{Bcl}-\mathrm{XL}$, as well as anoikis resistance of the radiation-surviving non-adherent cells is controlled by Erk1/2 activity.

Simultaneous inhibition of Erk1/2 and Akt pathways has an additive radiosensitizing effect. Enhanced Erk and $\mathrm{PI} 3 \mathrm{~K}-$ Akt signaling contribute to chemo- and radioresistance of CaP. ${ }^{5,8,33}$ Therefore, we exposed DU145 cells to 10 daily fractions of $2 \mathrm{~Gy}$ in the presence or absence of chemical inhibitors of Erk1/2, Akt or their combination (Supplementary Figure $6 \mathrm{~b}$ ) and followed survival and proliferation of non-adherent and adherent cells, respectively. Inhibition of Erk1/2 alone eliminated any live non-adherent cells, while Akt inhibition alone impacted survival of the non-adherent cells only modestly (Figure 6a) correlating with low Akt activity in this fraction (Figure 5a). The combined inhibitors suppressed survival of IR-exposed non-adherent cells and, importantly, showed a greater anti-proliferative effect than treatment with either inhibitor alone on the IR-resistant adherent $\mathrm{CaP}$ cells (Figures $6 \mathrm{a}$ and $\mathrm{c}$; Supplementary Figure 6a). Furthermore, the observed anti-proliferative effect of the combined inhibitors was greater among the irradiated, compared with non-irradiated $\mathrm{CaP}$ cells (Figures $6 \mathrm{~b}$ and $\mathrm{c}$ ). In contrast to $\mathrm{CaP}$ cells, normal human diploid BJ fibroblasts treated with the radiosensitizing 


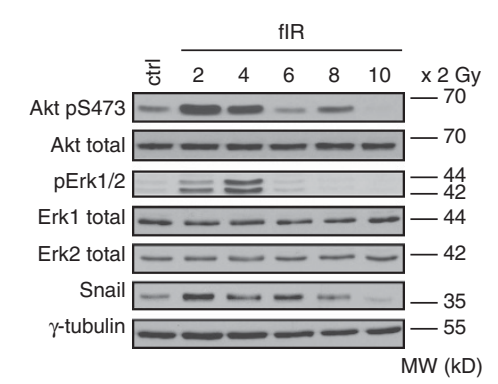

C

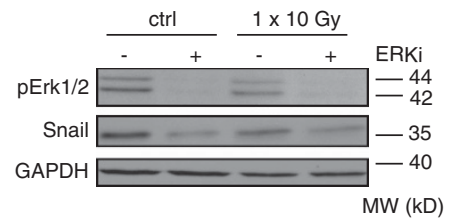

e

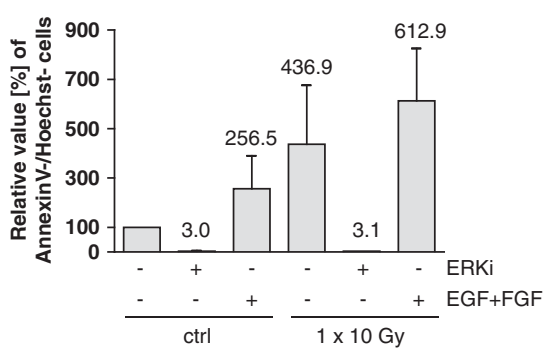

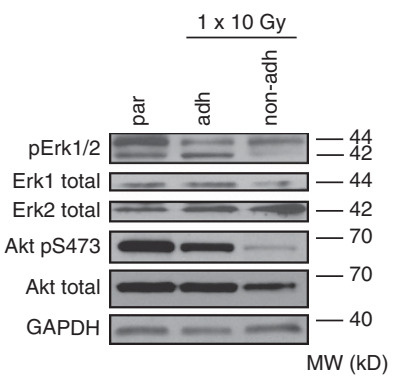

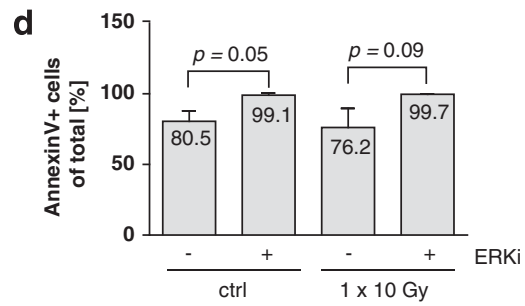

f

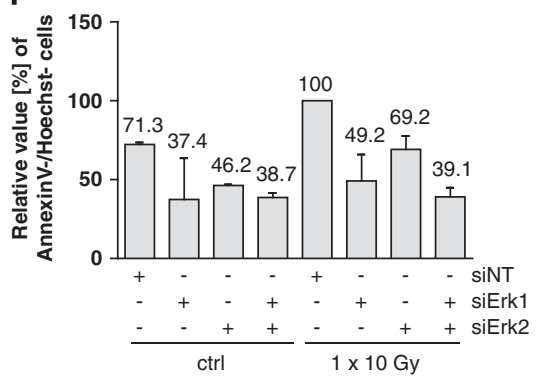

g

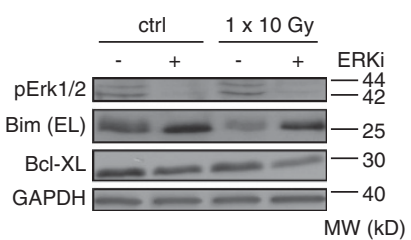

h

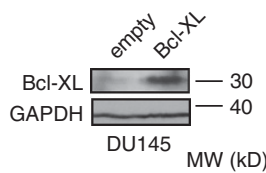

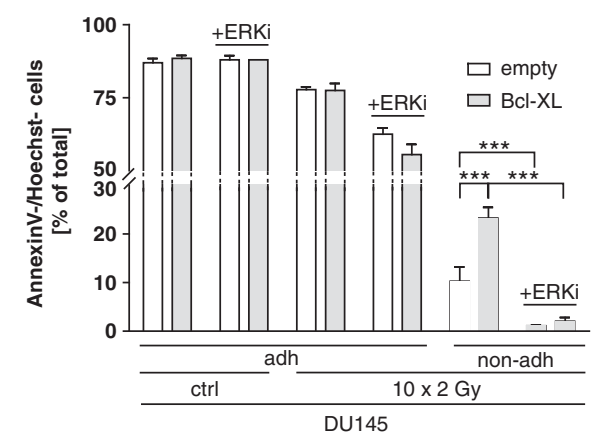

Figure 5 Effect of Erk1/2 inhibition on viability of fIR-surviving non-adherent DU145 cells. (a) Immunobloting detection of total Akt, phosphoserine 473 of Akt, total Erk1 and Erk2, phosphothreonine 204/phosphotyrosine 204 of Erk (pErk1/2) and Snail in control and irradiated (2 - $10 \times 2$ Gy) DU145 cells. Gamma-tubulin was used as a loading control. (b) Immunoblotting detection of total Erk1 and Erk2, phosphothreonine 204/phosphotyrosine 204 of Erk1/2 (pErk1/2), total Akt and phosphoserine 473 of Akt in control (parental) and irradiated $(1 \times 10 \mathrm{~Gy})$ adherent and non-adherent DU145 cells. GAPDH was used as a loading control. (c) Immunoblotting estimation of inhibition of Erk1/2 activity by Erk inhibitor U0126 (ERKi) detected as phosphothreonine 204/phosphotyrosine 204 of Erk (pErk1/2) and its effect on Snail expression in control and irradiated (1 $\times 10$ Gy) DU145 cells. GAPDH was used as a loading control. (d) Effect of Erk1/2 inhibition by ERKi on cell survival in control or irradiated ( $1 \times 10$ Gy) non-adherent DU145 cells assessed by flow cytometry 48 hours after IR. Bars represent relative amount (in percentage, numbers above bars) of apoptotic cells (AnnexinV ${ }^{+} / \mathrm{Hoechst}^{+}$plus AnnexinV $^{+} / \mathrm{Hoechst}^{-}$) in total non-adherent fraction. (e) Effect of Erk1/2 activation (mixture of $10 \mathrm{ng} / \mathrm{ml}$ EGF and $50 \mathrm{ng} / \mathrm{ml} \mathrm{FGF)} \mathrm{or} \mathrm{chemical} \mathrm{inhibition} \mathrm{(ERKi)} \mathrm{on} \mathrm{cell} \mathrm{survival} \mathrm{assessed} \mathrm{by} \mathrm{flow} \mathrm{cytometry} \mathrm{in} \mathrm{control}$ or irradiated $(1 \times 10$ Gy) non-adherent DU145 cells analyzed $48 \mathrm{~h}$ after IR by flow cytometry. Bars represent relative amount (in percentage, numbers above bars) of viable AnnexinV ${ }^{-} /$Hoechst $^{-}$cells in non-adherent fraction. Non-treated cells were set as 100\%. (f) Effect of siRNA-mediated knockdown of Erk1 (siErk1) and Erk2 (siErk2) on cell survival in control or irradiated $(1 \times 10 \mathrm{~Gy})$ non-adherent DU145 cells analyzed $48 \mathrm{~h}$ after IR and $72 \mathrm{~h}$ after transfection by flow cytometry. Non-targeting siRNA (siNT) was used as a negative control. The bars represent relative amount (in percentage, numbers above bars) of viable AnnexinV ${ }^{-} / \mathrm{Hoechst}^{-}$cells in non-adherent fraction. Irradiated cells transfected with control siRNA (siNT) were set as 100\%. (g) Effect of Erk1/2 inhibition (ERKi) on Bim (EL) and Bcl-XL levels in control or irradiated (1 $\times 10 \mathrm{~Gy}$ ) DU145 cells assessed by immunoblotting. GAPDH was used as a loading control. (h) Immunobloting detection of Bcl-XL in DU145 stable cell lines generated by infection with lentiviruses possesing pCDH-CMV-MCS-EFI-Neo-empty (empty) or pCDH-CMV-MCS-EFI-Neo-Bcl-XL (BCl-XL) vector. GAPDH was used as a loading control. (i) Effect of ERKi (10 $\mu \mathrm{M}$ for $16 \mathrm{~h}$, added after last dose of flR) on cell survival in control or irradiated $(10 \times 2 \mathrm{~Gy})$ adherent and non-adherent stable DU145 cells constitutively expressing Bcl-XL (Bcl-XL) analyzed by flow cytometry. The bars represent relative amount (in percentage) of viable (AnnexinV ${ }^{-} / \mathrm{Hoechst}^{-}$) cells. Stable DU145 cell line transduced with pCDH-CMV-MCSEFI-Neo-empty vector (empty) was used as a control. Data in $\mathrm{d}$-f represent means \pm S.D. from two independent experiments. Data in $\mathrm{i}$ represent means \pm S.D from four (w/o ERKi) or two ( + ERKi) independent experiments performed in duplicates. ${ }^{* \star *} P<0.001$ 
a

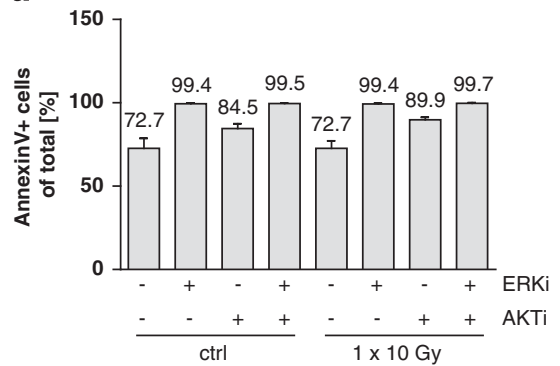

C

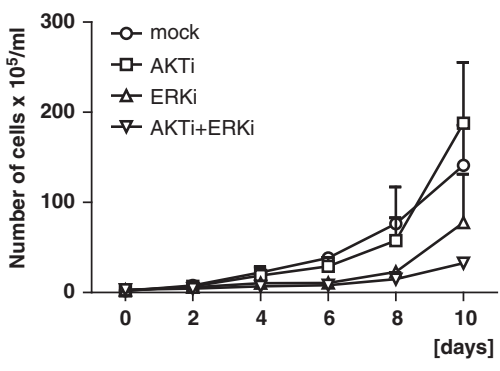

b
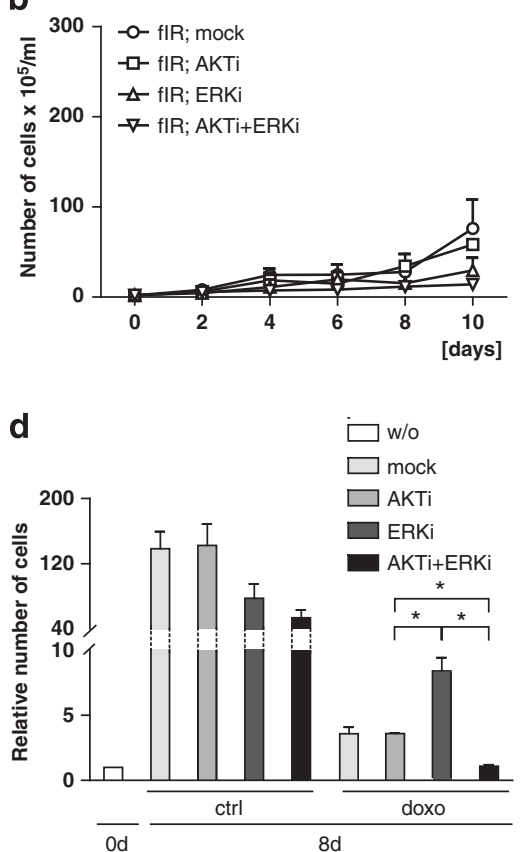

Figure 6 Differential sensitivity of flR-surviving adherent and non-adherent DU145 cells to inhibitors of Erk and Akt signaling. (a) Effect of Erk1/2 inhibition (ERKi) and/or Akt inhibition (AKTi) on cell survival in control or irradiated $(1 \times 10 \mathrm{~Gy})$ non-adherent DU145 cells analyzed by flow cytometry $48 \mathrm{~h}$ after IR. The bars represent relative amount (in percentage, numbers above bars) of apoptotic cells (AnnexinV ${ }^{-} /$Hoechst $^{-}$plus AnnexinV ${ }^{+} /$Hoechst $^{-}$) in total non-adherent fraction. (b) Effect of Erk1/2 inhibition (ERKi) and/or Akt inhibition (AKTi) on proliferation of irradiated (10 $\times 2$ Gy) DU145 cells. Trypan blue-negative cells were counted at time points as indicated. (c) Effect of Erk1/2 inhibition (ERKi) and/or Akt inhibition (AKTi) on proliferation of control non-irradiated DU145 cells. Trypan blue-negative cells were counted at time points as indicated. (d) Effect of Erk1/2 inhibition (ERKi) and/or Akt inhibition (AKTi) on proliferation of control or doxorubicine-treated $(0.75 \mu \mathrm{M})$ DU145 cells. Relative numbers of cells were assessed at day 0 (w/0; without any additives) and day 8 . Data in all bars are normalized to control cells (i.e. to doxorubicin-untreated cells) at day 8 . Data in a-d represent mean values \pm S.D. from two independent experiments. ${ }^{*} P<0.05$. In $\mathbf{b}$-d, control cells were treated with DMSO diluent (mock)

concentrations of both inhibitors only slowed down proliferation without cytotoxic effects (Supplementary Figure 6c).

Complementary to the radiosensitization experiments, the combined inhibition of Akt and Erk1/2 completely suppressed also $\mathrm{CaP}$ chemoresistance, otherwise manifested as outgrowth of senescence-resistant colonies of DU145 cells exposed to a subapoptotic, senescence-inducing treatment with doxorubicin (Figure 6d).

Overall, the combined inhibition of Akt and Erk1/2 impaired survival of the anoikis-resistant non-adherent $\mathrm{CaP}$ cells and prevented escape from senescence in the adherent $\mathrm{CaP}$ population both after irradiation and doxorubicin treatment.

\section{Acquired radioresistance of CaP cells after fractioned} irradiation. Conceptually and therapeutically relevant issue is whether the adherent or the non-adherent cells feature 'radioresistance memory', that is, enhanced survival on later round(s) of irradiation. We noted that the phenotypic switch (the cycle of irradiation-induced loss of adhesion and subsequent re-adhesion) was repeatable at least three times (not shown) indicating stress-induced reversible phenotypic plasticity. However, several population doublings of the re-adherent cells were necessary to revert the mesenchymal phenotype back to the epithelial one (see Supplementary Figure 7a. for changes in E-cadherin and vimentin after re-adhesion). To assess whether the fIR survivors are more radioresistant than the parental cells, we exposed DU145 cells that survived the 35 doses of 2 Gy as either adherent (adherent survivors) or non-adherent fraction after its re-adhesion (re-adherent survivors) to a single dose of 10 or 40 Gy. Although the overall survival of both adherent and re-adherent survivors did not differ markedly from the parental cells (Figure 7a) and the colony-forming ability was increased only for the adherent survivors compared to the parental cells (Figure 7b; consistent with Skvortsova et al. ${ }^{5}$ ), the colonies of the re-adherent survivors (although equally numerous as from the parental cells) featured fewer colonies composed of senescent-like cells (Figure 7b). Importantly, the anoikis-resistant survival of the re-adherent survivors was enhanced compared with both the parental cells and adherent survivors (Figure 7c).

Altogether, the observed radiation-induced phenotypes likely reflect contributions from both adaptive (partly transient) responses due to plasticity of the metastatic $\mathrm{CaP}$ cell populations, and more durable (heritable), selection-acquired resistance to radiation-evoked cellular senescence or anoikis (Supplementary Figure 7b).

\section{Discussion}

As metastatic $\mathrm{CaP}$ is essentially incurable due to radioresistance and chemoresistance, we performed this study to better understand the underlying mechanisms to overcome the resistance. Our analyses of human metastatic CaP cell lines DU145, PC-3, LNCaP and 22RV1 during a fractionated ionizing irradiation regimen that mimicked the schedule used 

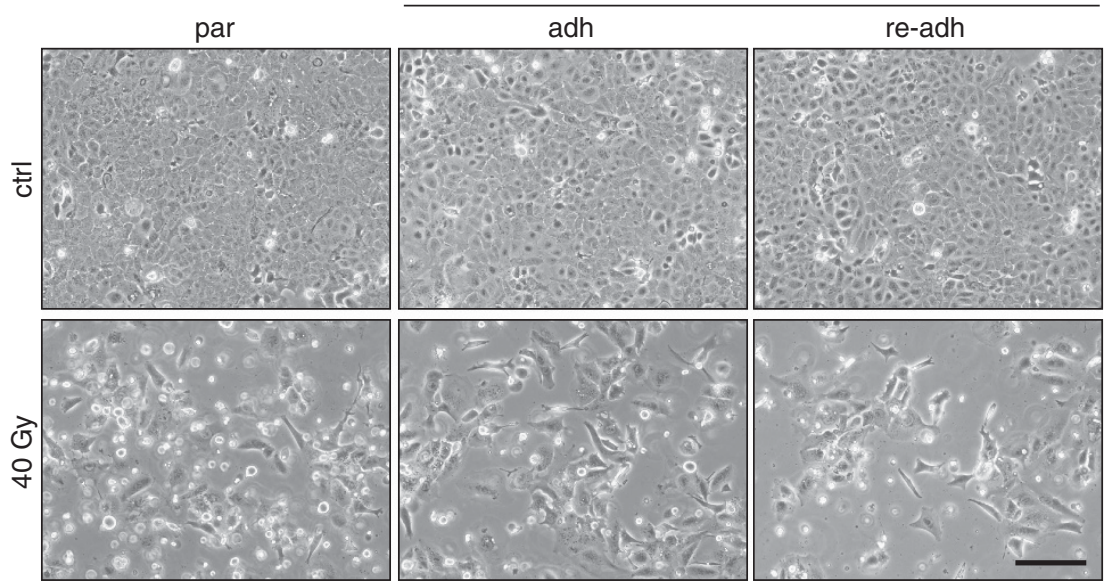

b

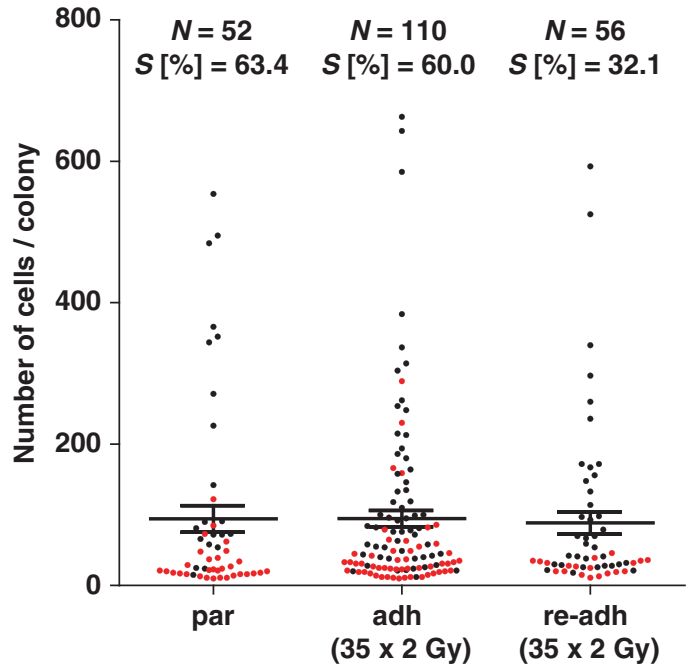

standard morphology

senescent morphology

C

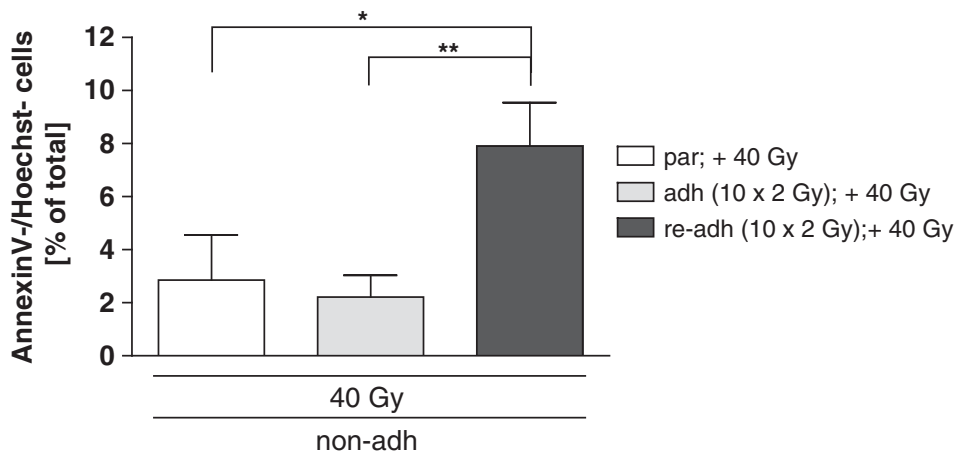

Figure 7 Evaluation of radioresistance of flR-surviving cells. (a) Phase contrast microscopic images of parental (par) and irradiated ( $35 \times 2$ Gy) adherent (adh) and re-adherent (readh) DU145 survivors 3 days after a single dose (40 Gy) or without re-irradiation (ctrl). Scale bar, $100 \mu \mathrm{m}$. (b) Clonogenic cell survival assay. Parental or irradiated ( $35 \times 2$ Gy) adherent and re-adherent DU145 survivors were counted and $1 \times 10^{3}$ cells seeded into 6 -well plates in triplicates. Number of cells from all colonies ( $>10$ cells) formed at day 13 following re-irradiation ( $10 \mathrm{~Gy}$ ) were counted and plotted. $N=$ number of total colonies formed. $S=$ number of senescent colonies formed/ number of total colonies formed $\times 100$. Each dot in the plot represents one colony characterized by number of cells and presence (red dot) or absence (black dot) of senescence according to cell morphology. (c) Anoikis-resistant survival of parental (par) and previously irradiated (10 × 2 Gy) adherent (adh) and re-adherent (readh) DU145 survivors after re-irradiation ( $40 \mathrm{~Gy}$ ) assessed by flow cytometry $72 \mathrm{~h}$ after IR. Bars represent relative amount (in percentage) of viable cells (AnnexinV ${ }^{-} / \mathrm{Hoechst}^{-}$) in total non-adherent fraction. Data represent mean values \pm S.D. from three independent experiments performed in duplicates. ${ }^{*} P<0.05 ;{ }^{* \star} P<0.01$

in clinical radiotherapy revealed three phenotypically distinct radiation-surviving cell populations: (1) adherent cells with senescent/EMT features capable of regrowth after termination of irradiation; (2) non-adherent anoikis-resistant and non-proliferating cells with stem cell traits capable of long-term survival, competent to restore adherent growth and 
proliferation; (3) re-adherent cells originating from the non-adherent pool, with epithelial features and tumorigenic potential.

One of our key novel results was the role of the Snail-ERK pathway in the EMT phenotype, loss of adherence, anoikis and radioresistance. Our findings of decreased E-cadherin in the radiation-surviving non-adherent cells, accompanied by enhanced levels of the E-cadherin-repressive EMT-inducer Snail, ${ }^{21,22}$ support the role of E-cadherin-mediated intercellular contacts in the maintenance of the epithelial phenotype,${ }^{34}$ the loss of E-cadherin per se as an EMT inducer, ${ }^{35}$ and association of EMT with radio- and chemoresistance. ${ }^{36-39}$ Using MEKi and knockdown of Erk1/2 and Snail, we showed that the loss of adhesion after IR required Erk1/2-mediated expression of Snail. Consistent changes in gene expression, including Snail upregulation, and genes of the Notch pathway, have been independently validated by a comprehensive gene expression profiling analysis (not shown). The radiationinduced phenotypic heterogeneity, we report, might reflect transient cellular plasticity as well as stress-evoked responses of preexistent subsets cells seen in the parental DU145 and PC-3 cell populations. ${ }^{40-52}$

Ionizing radiation can promote traits of EMT in normal human mammary epithelium, ${ }^{41}$ lung carcinoma ${ }^{42,43}$ and colorectal cancer cells. ${ }^{44}$ Furthermore, besides their role in E-cadherin repression, ${ }^{4,46}$ Slug and Snail have been implicated in radioresistance-associated EMT.47,48 Snail enhances resistance to apoptosis by activating the PI3K/Akt and Erk1/2 pathways, ${ }^{28}$ consistent with our data showing increased radiosensitivity after inhibition of PI3K/Atk and Erk $1 / 2$ and downregulation of Snail. Notably, Snail is a substrate of the major radiation-induced kinase ATM, and this phosphorylation is involved in radiosensitivity. ${ }^{49}$

Another intriguing aspect of our results is the link between EMT and stem-like cell traits. Epithelial cancer cells undergoing EMT exhibit also features of stemness, ${ }^{50,51}$ and Snail induces both EMT and stem cell-like features in squamous cell carcinoma. ${ }^{52}$ We show that besides elevated Snail, radiation-surviving non-adherent $\mathrm{CaP}$ cells featured enhanced expression of stem cell-associated genes CD133, ${ }^{53}$ Oct-4, Sox2 and Nanog, the latter three capable of reprogramming various differentiated cells toward stemness. ${ }^{54,55}$ Besides these stem cell markers, radiation-surviving non-adherent $\mathrm{CaP}$ cells showed increased activity of Notch signaling, a characteristics of diverse progenitor cells. ${ }^{23,24}$ In breast cancer, IR induces Notch ${ }^{56}$ and stem-like phenotype, including Notch-dependent upregulation of Oct-4. ${ }^{57}$ Notch signaling can also activate EMT. ${ }^{58}$ Together with other evidence, ${ }^{59-61}$ our data support an emerging concept that IR promotes a phenotypic switch towards EMT and stem-like traits in epithelial tumors, also consistent with the intriguing yet mechanistically unclear resistance of cancer stem-like cells to genotoxic treatments.

In contrast to reported sphere-forming growth of irradiated lung cancer cells ${ }^{43}$ and IR-induced cell cycle entry of breast CSC, ${ }^{61}$ the radiation-induced non-adherent CaP cells were proliferatively dormant even in conditions permissive for self-renewal of CSCs (not shown). This supports the notion that EMT-inducing factors reduce cell proliferation, ${ }^{28,62}$ and circulating tumor cells (CTCs) with enhanced Twist1 need to downregulate Twist1 before regaining the ability to proliferate and form macrometastases. ${ }^{63}$ We propose that during development of radioresistance in $\mathrm{CaP}$, and possibly other types of cancer, reversion of EMT is necessary for initiation of cell proliferation. This is also supported by our data that the readherent $\mathrm{CaP}$ cells exhibited an epithelial phenotype and reduced motility (not shown) indicating reversion of stem-like/ mesenchymal traits during re-adhesion. The phenotypic changes including cell contact and ECM-adhesive molecules observed in the non-adherent irradiated population reverted after cell re-adhesion, coinciding with regained proliferation and tumorigenicity.

There is evidence that EMT/MET is linked with metastatic spread, as the number of CTCs with epithelial or mesenchymal phenotype captured from patients treated for metastatic breast cancer correlated with type of therapy applied. ${ }^{64}$ Whereas positive therapeutic responses were accompanied by fewer CTCs and increased epithelial phenotype, patients with progressive disease unresponsive to chemotherapy possessed higher numbers of predominantly mesenchymal CTCs in post-treatment samples. The simultaneous inhibition of Erk and PI3K-Akt signaling we report here resulted in both suppression of resistance to anoikis and prevention of regrowth of adherent $\mathrm{CaP}$ in response to IR and doxorubicin, indicating potential use of this drug combination for radio and chemosensitization with abrogation of radio-/chemotherapyinduced tumor cell heterogeneity. Mechanistically, we speculate that DNA damage signaling from therapy-induced recurrent and/or persistent DNA lesions (e.g. from senescent cells $^{65}$ ) may promote the observed phenotypic switch via the ATM-induced cytokine network ${ }^{66}$ including TGF $\beta$ family members that can shape the phenotype of treated cancer cells toward EMT and stem cell enrichment in a paracrine manner. Finally, we suggest that such treatment resistance (see Supplementary Figure 7) could be overcome, and that the dependency on signaling cascades we report here reveal vulnerabilities potentially exploitable in cancer treatment.

\section{Materials and Methods}

Chemicals and antibodies. MEK-Erk inhibitor U0126 (ERKi; $10 \mu \mathrm{M})$, Akt1/2 kinase inhibitor (AKTi; $1 \mu \mathrm{M}$; Cat. No. A6730) doxycycline hydrochloride (dox) and doxorubicin hydrochloride (doxo), were purchased from Sigma (St Louis, MO, USA). Epidermal growth factor (EGF) and fibroblast growth factor (FGF) recombinant proteins were obtained from Peprotech (Rocky Hill, NJ, USA).

The following antibodies were used for immunoblotting: mouse monoclonal antibody against Erk1 (ECM Bioscience, Versailles, KY, USA), goat polyclonal antibody against DLL1 and mouse monoclonal antibody against Twist1 from Santa Cruz Biotechnology (Dallas, TX, USA), rabbit monoclonal antibodies against Snail (SNAl1), Akt, Nanog XP, Oct-4A, Bcl-XL and phosphoserine 473 of Akt, rabbit polyclonal antibodies against Chk2, p53 and Bim and mouse monoclonal antibodies against p2 $1^{\text {wat/cip }}$, phosphoserine 15 of p53 and phosphothreonine 68 of Chk2, all from Cell Signaling Technology (Danvers, MA, USA). Mouse monoclonal antibody against GAPDH was purchased from GeneTEX (Irvine, CA, USA), mouse monoclonal antibody against phosphoserine 139 of histone H2AX from Millipore (Billerica, MA, USA), mouse monoclonal antibody against E-cadherin from BD Biosciences (San Jose, CA, USA) and rabbit polyclonal antibody against phosphothreonine 202/phosphotyrosine 204 of Erk1/2 from Promega (San Luis Obispo, CA, USA). Mouse monoclonal antibody against $\gamma$-tubulin was provided by Pavel Draber (Institute of Molecular Genetics, Prague, Czech Republic). Mouse monoclonal antibody against Erk2 (B3B9) was prepared by Mike Weber and provided by Tomas Vomastek (Institute of Microbiology, Prague, Czech Republic).

The following antibodies were used for indirect immunofluorescence: mouse monoclonal antibody PG-M3 against PML, rabbit polyclonal antibody against 53BP1 
both from Santa Cruz Biotechnology, mouse monoclonal antibody against phosphoserine 139 of histone H2AX (Millipore), mouse monoclonal antibody against E-cadherin from BD Biosciences, rabbit polyclonal antibodies against vimentin from Cell Signaling Technology. Secondary antibodies anti-mouse IgG conjugated with Cy3 from Jackson Immunoresearch Laboratories (West Grove, PA, USA), anti-rabbit IgG antibody Alexa 568 and anti-mouse IgG antibody Alexa 488 were from Invitrogen (Carlsbad, CA, USA).

Cell cultures. Human prostatic carcinoma cell lines DU145, PC-3, LNCaP, 22RV1, human breast carcinoma cell line MCF-7, human embryonic kidney cells HEK293T stably expressing the SV40 large T antigen and human fibroblast cells BJ were obtained from American Type Culture Collection (ATCC, Manassas, VA, USA). DU145, PC-3, MCF-7 and HEK293T cells were cultivated in DMEM (glucose $4.5 \mathrm{~g} /$ ), LNCaP and 22RV1 in RPMI-1640 (both media from Biochrom, Cambridge, UK) and BJ in DMEM (glucose $1 \mathrm{~g} /$ /; Invitrogen) supplemented with $10 \%$ fetal bovine serum (PAA, Pasching, Austria), $100 \mathrm{U} / \mathrm{ml}$ penicillin and $100 \mu \mathrm{g} / \mathrm{ml}$ streptomycin sulfate (Sigma). Cells were kept at $37^{\circ} \mathrm{C}$ under $5 \% \mathrm{CO}_{2}$ atmosphere and $95 \%$ humidity.

Cells were irradiated with orthovoltage X-ray instrument T-200 (Wolf-Medizintechnik GmbH, St. Gangloff, Germany) using $0.5 \mathrm{~Gy} / \mathrm{min}$ dose rate and thorium filter daily with 10 or 35 doses 2 Gy (fIR) or with single dose $10 \mathrm{~Gy}$. Non-adherent cells generated during fIR were collected both during fIR $(35 \times 2 \mathrm{~Gy})$ or $24 \mathrm{~h}$ after last dose ( 10 or $35 \times 2$ Gy). There was no analytical difference between these two modes of cell collection. However, to avoid possible contamination of non-adherent fraction by mitotic cells of adherent fraction $(10 \times 2 \mathrm{~Gy} f \mathrm{fR})$, non-adherent cells were transferred through another cultivation flask to enable attachment of mitotic cell contaminants (6-8 h), then moved to a new flask and daily carefully checked for 'prematurely' attached cells. Using such procedure, potential contamination was practically eliminated.

To obtain re-adherent colonies from non-adherent cells, irradiated non-adherent prostate cancer cells were separated from adherent fraction as stated above and observed for initiation of adherent growth. After re-adherence, cells were cultivated as described above. As non-adherent control, DU145 cells were kept in confluence for 3-5 days and then non-adherent cells were collected.

Images of live cells were captured by inverted tissue culture microscope Nicon Eclipse TE300 (Nicon, Tokyo, Japan) equipped with Leica DFC490 camera and LAS AF software (Leica Microsystems, Germany).

Lentiviral constructs and transduction. Lentiviral vector $\mathrm{PCDH}-\mathrm{EFI}-$ $\mathrm{Neo}-\mathrm{Bcl}-\mathrm{XL}$, constitutively expressing $\mathrm{Bcl}-\mathrm{XL}$, was generated by subcloning the EcoRl fragment from pSFFV-Neo-Bcl-XL (\#8749 Addgene, Cambridge, MA, USA) into PCDH-CMV-MCS-EFI-Neo (Systems Biosciences, CA, USA). pLKO-Tet-OnshRNA-Snail was generated by ligation of the double stranded oligo $5^{\prime}$-CCGGCCA GGCTCGAAAGGCCTTCAACTCGAGTTGAAGGCCTTTCGAGCCTGGTTTTT-3' between the Agel and EcORI sites in the pLKO-Tet-On vector as described. ${ }^{67} \mathrm{To}$ produce DU145-empty and DU145-Bcl-XL cell lines, DU145 cells were transduced either with pCDH-CMV-MCS-EFI-Neo or with pCDH-EFI-Neo-BCl-XL viral particles. ${ }^{68}$ For inducible RNAi of Snail, DU145 were transduced with pLKO-TetOn-shRNA-Snail particles. To obtain stabile expression, $72 \mathrm{~h}$ post transduction cells were plated into media containing G418 $(800 \mu \mathrm{g} / \mathrm{ml})$ or puromycin $(2 \mu \mathrm{g} / \mathrm{ml})$ and selected for further 10 or 3 days. Snail shRNA expression was induced with $0.7 \mu \mathrm{g} / \mathrm{ml}$ doxycycline (dox), supplied every $48 \mathrm{~h}$ to the cultivation media. Non-transduced DU145 cells (wt) treated with corresponding amounts of dox were used as a control.

Magnetic-activated cell sorting. AnnexinV-negative fraction of irradiated non-adherent DU145, PC-3 and MCF-7 cells was obtained by incubation with Dead Cell Removal MicroBeads (Dead Cell Removal Kit, Miltenyi Biotec, Germany) for $15 \mathrm{~min}$ and separation in magnetic field of AutoMACS Pro magnetic separator (Miltenyi Biotec). The separated cells were harvested for immunoblotting or real time qRT-PCR analysis.

\section{Fluorescence-activated cell sorting}

AnnexinV-FITC/Hoechst 33258 staining and analysis: Cell survival of non-adherent DU145, PC-3, LNCaP, MCF-7 and 22RV1 cells after single dose or multiple doses of IR was assessed by staining with $1-5 \mu \mathrm{g} / \mathrm{ml} \mathrm{Hoechst} 33258$ (Invitrogen) in combination with AnnexinV-FITC (AnnexinV: FITC Apoptosis Detection Kit, BD Biosciences) according to manufactureís protocol. Cells were collected in PBS ( $300 \mathrm{~g}$ at $4{ }^{\circ} \mathrm{C}$ for $10 \mathrm{~min}$ ), stained in AnnexinV binding buffer
(BD Biosciences) for $15 \mathrm{~min}$ at RT and then analyzed using the LSRIl flow cytometer (BD Biosciences). Cells from following quadrants were analyzed: viable

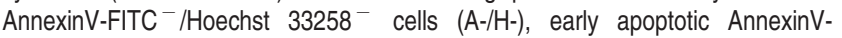
$\mathrm{FITC}^{+} /$Hoechst $33258^{-}$cells $(\mathrm{A}+/ \mathrm{H}-)$ and late apoptotic AnnexinV ${ }^{+} /$Hoechst $33258^{+}$cells $(A+/ H+)$. To assess radiation-induced loss of adhesion, non-adherent control and irradiated cells $(1 \times 10 \mathrm{~Gy})$ were washed twice with PBS and collected ( $300 \mathrm{~g}$ at $4^{\circ} \mathrm{C}$ for $5 \mathrm{~min}$ ) in $300 \mu$ l of AnnexinV binding buffer (BD Biosciences). Defined volume of cell suspension was analyzed to assess the total number of cells. The precision of volume intake by high throughput sampler (HTS) unit of LSRII flow cytometer was checked using fluorescent AlignFlo Flow Cytometry Alignment Beads, $2.5 \mu \mathrm{m}$ (Invitrogen) excitable at $488 \mathrm{~nm}$. Volume intake error was estimated as $\pm 5.13 \%$.

eFluor670 staining and analysis: Proliferation of irradiated adherent DU145 cells was estimated with Cell Proliferation Dye eFluor670 (eBioscience, San Diego, CA, USA), which binds unspecifically membrane proteins and is distributed equally between daughter cells during division. Dye fluorescence intensity in APC channel was measured by LSRII flow cytometer. Control and irradiated adherent cells were detached by Versene after 10th dose of irradiation (Gibco, Carlsbad, CA, USA), stained with eFluor670 and either immediately analyzed by FACS or further irradiated (five daily doses of 2 Gy) and analyzed after 11,13 and 15 dose. To assess the proliferation of irradiated ( $10 \times 2 \mathrm{~Gy})$ non-adherent cells, cells were collected in PBS after last dose of irradiation $\left(300 \mathrm{~g}\right.$ at $4{ }^{\circ} \mathrm{C}$ for $10 \mathrm{~min}$ ), stained with eFluor670 and further cultivated in new Petri dish for 28 days. At 28 th day after staining, non-adherent and newly established re-adherent cells were analyzed by FACS as described above.

Click-iT EdU proliferation assay and analysis: Proliferation of nonadherent DU145 cells was assessed during fIR (after $7 \times 2$ Gy and $10 \times 2 \mathrm{~Gy}$ ) and at several post-fIR time points (3,7 and 10 days after fIR). First, cells were pulselabeled with $10 \mu \mathrm{M}$ EdU for $3 \mathrm{~h}$, washed with PBS and stained with fixable viability fluorescent dye eFluor780 (eBioscience) according to manufactureŕs protocol. Second, cells were fixed ( $4 \%$ formaldehyde, $15 \mathrm{~min}$ at RT), washed twice with PBS and stored at $4{ }^{\circ} \mathrm{C}$. In the post-fIR time points, medium with non-adherent cells was transferred to a new Petri dish 1 day before EdU pulse to prevent mitotic cell contamination from adherent layer. DNA replication was measured using the Click-iT EdU Alexa Fluor 488 Imaging Kit (Invitrogen), customized for flow cytometry. EdU was detected after permeabilization $(0.2 \%$ Triton X-100, 5 min at RT) by staining cells with Click-iT chemistry for $25 \mathrm{~min}$ at RT (azide labeled by Alexa Fluor 488, $\mathrm{CuSO}_{4}$ and EdU buffer additive in $100 \mathrm{mM}$ Tris, pH 8.5). Samples were analyzed using LSRII flow cytometer with $488 \mathrm{~nm}$ excitation. Background values were estimated by measuring non-EdU labeled, but Click-iT chemistry stained cells.

Indirect immunofluorescence. Cells grown on glass coverslips were fixed by methanol:acetone $(1: 1)$ at $4{ }^{\circ} \mathrm{C}$ or by $4 \%$ formaldehyde at RT and permeabilized by $0.2 \%$ Triton X-100 $15 \mathrm{~min}$ at RT. After washing with PBS, cells were incubated in 10\% FBS diluted in PBS to block unspecific signal. Cells were subsequently incubated with diluted primary antibodies for $1 \mathrm{~h}$ at RT and then extensively washed with PBS. The incubation with secondary antibodies was performed for $1 \mathrm{~h}$ at RT. Nuclei were counterstained with 4',6-diamidino-2phenylindole staining (DAPI; Sigma) followed by mounting in Mowiol (Sigma) or Vectashield HardSet Mounting Medium containing DAPI (Vector Laboratories, Burlingame, CA, USA). Images were captured by fluorescent microscope Leica CTR6000 (Leica Microsystems) equipped with monochrome digital camera DFC350 FX and Leica LAS AF Lite software or Zeiss Axio Imager.A2 equipped with Zeiss AxioCam HR camera and Metamorph software.

SDS-PAGE and immunoblotting. Cells were washed with PBS, harvested into Laemmli SDS sample lysis buffer ( $2 \%$ SDS, $50 \mathrm{mM}$ Tris-HCl, $10 \%$ glycerol in double-distilled $\left.\mathrm{H}_{2} \mathrm{O}\right)$ and sufficiently sonicated $(3 \times 15$ seconds at 4 micron amplitude with $15 \mathrm{sec}$ cooling intervals) on Soniprep 150 (MSE, London, UK). Concentration of proteins was estimated by the BCA method (Pierce Biotechnology, IL, Rockford, USA). A quantity of $100 \mathrm{mM}$ DTT and $0.01 \%$ bromphenol blue was added to lysates before separation by SDS-PAGE (10 and $12 \%$ gels were used). The same protein amount ( 25 or $30 \mu \mathrm{g}$ ) was loaded into each well. Proteins were electrotransferred onto a nitrocellulose membrane using wet transfer and detected by specific antibodies combined with horseradish peroxidase-conjugated secondary antibodies (goat anti-rabbit, goat anti-mouse, 
Bio-Rad, Hercules, CA, USA). Peroxidase activity was detected by ECL (Pierce Biotechnology) or SuperSignal West Femto Substrate (Thermo Fisher Scientific, Waltham, MA, USA). GAPDH or $\gamma$-tubulin was used as a marker of equal loading.

Quantitative real time PCR. Total RNA samples were isolated using RNeasy Mini Kit (Qiagen Sciences, Germantown, MD, USA) as described. ${ }^{69}$ Briefly, first strand cDNA was synthesized from $200 \mathrm{ng}$ of total RNA with random hexamer primers using High-Capacity cDNA Reverse Transcription kit (Applied Biosystems, Foster city, CA, USA).

qRT-PCR was performed in ABI Prism 7300 (Applied Biosystems) using SYBR Select Master Mix containing SYBR GreenE dye (Applied Biosystems). The relative quantity of CDNA was estimated by $\triangle \triangle C T$ method and data were normalized to RPL37a, GAPDH or $\beta$-actin. Following primers were purchased from East Port (Prague, Czech Republic): Snail (SNAl1): $5^{\prime}$-TGC CCT CAA GAT GCA CAT CCG A-3', 5'-GGG ACA GGA GAA GGG CTT CTC-3'; Slug (SNAI2): 5'-ATC TGC GGC AAG GCG TTT TCC A-3'; $5^{\prime}$-GAG CCC TCA GAT TTG ACC TGT C-3'; Twist1: $5^{\prime}$-GCC AGG TAC ATC GAC TTC CTC T-3', 5'-TCC ATC CTC CAG ACC GAG AAG G-3'; Zeb2: 5'-AAT GCA CAG AGT GTG GCA AGG C-3', 5' $5^{\prime}$-CTG CTGA TGT GCG AAC TGT AGG-3'; CDH1: 5'-TGA AGG TGA CAG AGC CTC TGG AT-3', 5'-TGA AGG TGA CAG AGC CTC TGG AT-3'; MMP-7: 5'-TCG GAG GAG ATG CTC ACT TCG A-3', 5'-GGA TCA GAG GAA TGT CCC ATA CC-3'; ITGA2: 5'-TTG CGT GTG GAC ATC AGT CTG G-3', $5^{\prime}$-GCT GGT ATT TGT CGG ACA TCT AG-3'; LAMA3: $5^{\prime}$-CCG ATA GTA TCC AGG GCT ACA AC-3', 5'-AAC CAG ATG AGC ATC ACA TTC CTG-3'; LAMC2: 5'-ACC TGT GAA GCG GTG ACA CTG-3', 5'-TAC AGA GCT GGA AGG CAG GAT G-3'; CD133: $5^{\prime}$-TTT TGC GGT AAA ACT GGC TAA-3', 5'-CCA TTT TCC ATA TTT TTC ATG G-3'; Sox2: 5'-CAA GAT GCA CAA CTC GGA GA-3', 5'-GCT TAG CCT CGT CGA TGA AC-3'; Oct-4: 5'-CAG CTT GGG CTC GAG AAG-3', 5'-CCT CTC GTT GTG CAT AGT CG-3'; Nanog: $5^{\prime}$-CTC CAA CAT CCT GAA CCT CAG C-3', 5'-CGT CAC ACC ATT GCT ATT CTT CG-3'; DLL1: 5'-TGC CTG GAT GTG ATG AGC AGC A-3', $5^{\prime}$-ACA GCC TGG ATA GCG GAT ACA C-3'; DLL4: 5'-CTG CGA GAA GAA AGT GGA CAG G-3', 5'-3'; Jag1: 5'-TGC TAC AAC CGT GCC AGT GAC T-3', 5'-TCA GGT GTG TCG TTG GAA GCC A-3'; Hes1: 5'-GGA AAT GAC AGT GAA GCA CCT CC-3', 5'-GAA GCG GGT CAC CTC GTT CAT G-3'; Hey1: 5'-TGT CTG AGC TGA GAA GGC TGG T-3', 5'-TTC AGG TGA TCC ACG GTC ATC TG-3' RPL37a: 5'-AGG AAC CAC AGT GCC AGA TCC-3', 5'-3'; GAPDH: 5'-GTC GGA GTC AAC GGA TTT GG-3'; $\beta$-actin: $5^{\prime}$-CCA ACC GCG AGA AGA TGA-3', 5'-CCA GAG GCG TAC AGG GAT AG- $3^{\prime}$. The data are expressed as the means \pm S.D. of a minimum of two independent experiments performed in triplicates. The $P$-values were estimated using two-tailed Student's $t$-test. $P$-values $<0.05$ were considered statistically significant.

Senescence-associated $\beta$-galactosidase assay. Staining for SA- $\beta$ Gal activity was performed by Senescence $\beta$-Galactosidase Staining Kit from Cell Signaling Technology according to manufactureís protocol. Coverslips were mounted in Mowiol containing 4',6-diamidino-2-phenylindole (DAPI; Sigma) and images were captured by fluorescent microscope Leica DM6000 (Leica Microsystems) equipped with color camera DFC490 and Leica LAS AF Lite software.

BrdU incorporation assay. Cells cultured on glass coverslips were pulselabeled with $10 \mu \mathrm{M} \mathrm{BrdU}$ (Sigma) for $24 \mathrm{~h}$ before fixation with $4 \%$ formaldehyde for $15 \mathrm{~min}$ at RT. After DNA denaturation in $2 \mathrm{M} \mathrm{HCl}(30 \mathrm{~min})$, cells were washed in PBS, incubated with mouse monoclonal antibody against BrdU (GeneTex). Images of cells with DAPI-counterstained nuclei were captured by fluorescence microscope Axio Imager.A2 (Zeiss, Germany) using Metamorph software (version 6.2r6; Molecular Devices, Sunnyvale, CA, USA).

siRNA-mediated gene knockdown. Specific siRNAs were introduced into cells using Lipofectamine RNAiMAX (Invitrogen). All siRNAs were purchased from Applied Biosystems. Non-targeting siRNA (siNT) sequences were used as a negative control siRNA. Sense sequences of used siRNAs are listed below: siErk1: 5'-GGA CCG GAU GUU AAC CUU Utt-3', siErk2: 5'-CAA CCA UCG AGC AAA UGA tt-3' siSnail: 5'-GAA UGU CCC UGC UCC ACA Att-3', siTwist1: 5'-AGA ACA CCU UUA GAA AUA Att-3'.

Cell proliferation. DU145 and BJ proliferation curves were estimated by counting trypan blue-negative cells with Countess automated cell counter (Invitrogen) every 2 days during 8-10 day time course. ERKi $(10 \mu \mathrm{M})$ and AKTi
$(1 \mu \mathrm{M})$ were changed with fresh culture medium every 2 days $30-45$ min before irradiation. Data represent the means \pm S.D. of two independent experiments.

Clonogenic cell survival assay. Clonogenic assay of control (parental) and irradiated 'radioresistant' (adherent and re-adherent) DU145 cells were performed as described. ${ }^{70}$ Briefly, cells were seeded on 6-well plates in triplicates and subsequently ( $6 \mathrm{~h}$ post seeding) irradiated with 10 or 40 Gy. Cells were fixed with ice-cold $100 \%$ methanol $\left(10 \mathrm{~min}\right.$ at $\left.-20^{\circ} \mathrm{C}\right)$ and stained with $0.5 \%$ crystal violet in $20 \%$ methanol (10 min at RT) at day 13th, and groups in excess of 10 cells were counted as colonies. In some experiments, the size of the colonies above the threshold and presence of senescence-like cells in colonies were examined.

Estimation of tumorigenicity. Immunodeficient male SCID mice (6 weeks old) purchased from AnLab, s.r.o. (Prague, Czech Republic) were acclimated for 2 weeks. Experimental protocols were approved by the Institutional Animal Care Committee of the Institute of Molecular Genetics ASCR, Prague. $1 \times 10^{5}$ or $1 \times 10^{6}$ control (parental) or irradiated (10 $\times 2$ Gy) re-adherent DU145 cells in $300 \mu \mathrm{l}$ of DMEM were injected subcutaneously into the right flank of the mice. Cells were stained with trypan blue and counted for viability using Countess automated cell counter before injection (Invitrogen). Tumor onset and tumor size were measured weekly with the use of calipers and calculated by length $\times$ width. $N=5$. Statistical significance was estimated by Newman-Keuls multiple comparison test.

Data processing and statistical analysis. FACS data were analyzed using FlowJo 9.6.4 cytometric analytical software (TreeStar, Stanford University, USA). Graphs were generated using Prism 5 (GraphPad Software, La Jolla, CA, USA). $P$-values were calculated using Student's $t$-test for two samples assuming unequal variances (Microsoft Excel 2010, Microsoft, Redmond, WA, USA).

\section{Conflict of Interest}

The authors declare no conflict of interest.

Acknowledgements. This study was supported by Grant Agency of the Czech Republic (Project 13-17658S), Institutional Grant (Project RVO 68378050), DiaNa21 (Smartbrain s.r.o.), the Danish Research Council (DFF-1331-00262B), the Lundbeck Foundation (R93-A8990), the Danish National Research Foundation, the European Commission (Project DDResponse 259893) and the Grant Agency of the Ministry of Health of the Czech Republic (Project NT14461). LK, SH and TI were supported in part by the Faculty of Science, Charles University, Prague. We acknowledge P. Hamerlik for helpful discussions, D. Hladovcova for help with the mouse model, M. Vancurova for technical assistance with cell culture, 0 . Horvath and Z. Cimburek for their help with flow cytometry and cell sorting, R. Liska and S. Pavelka for help with cell irradiation, L. Andera for providing the anti-Bcl-XL and RPL37a forward and reverse primers for qRT-PCR, J. Švadlenka for providing the $\mathrm{pCDH}-\mathrm{EFI}-\mathrm{Neo}-\mathrm{empty}$ and $\mathrm{pCDH}-\mathrm{EFI}-\mathrm{Neo}-\mathrm{BCl}-\mathrm{XL}$ lentiviral vectors, T. Vomastek for the anti-Erk2 antibody and P. Draber for the antigamma-tubulin antibody.

1. Jemal A, Bray F, Center MM, Ferlay J, Ward E, Forman D. Global cancer statistics. CA Cancer J Clin 2011; 61: 69-90.

2. Heidenreich A, Bellmunt J, Bolla M, Joniau S, Mason M, Matveev V et al. EAU guidelines on prostate cancer. Part 1: screening, diagnosis, and treatment of clinically localised disease. Eur Urol 2011; 59: 61-71.

3. Mottet N, Bellmunt J, Bolla M, Joniau S, Mason M, Matveev V et al. EAU guidelines on prostate cancer. Part II: treatment of advanced, relapsing, and castration-resistant prostate cancer. Eur Urol 2011; 59: 572-583.

4. Kong Z, Xie D, Boike T, Raghavan P, Burma S, Chen DJ et al. Downregulation of human DAB2IP gene expression in prostate cancer cells results in resistance to ionizing radiation. Cancer Res 2010; 70: 2829-2839.

5. Skvortsova I, Skvortsov S, Stasyk T, Raju U, Popper BA, Schiestl B et al. Intracellular signaling pathways regulating radioresistance of human prostate carcinoma cells. Proteomics 2008; 8: 4521-4533.

6. Sakai I, Miyake H, Terakawa T, Fujisawa M. Inhibition of tumor growth and sensitization to chemotherapy by RNA interference targeting interleukin- 6 in the androgen-independent human prostate cancer PC3 model. Cancer Sci 2011; 102: 769-775. 
7. Huang HF, Murphy TF, Shu P, Barton AB, Barton BE. Stable expression of constitutivelyactivated STAT3 in benign prostatic epithelial cells changes their phenotype to that resembling malignant cells. Mol Cancer 2005; 4: 2.

8. Kajanne R, Miettinen P, Tenhunen M, Leppa S. Transcription factor AP-1 promotes growth and radioresistance in prostate cancer cells. Int J Oncol 2009; 35: 1175-1182.

9. Kim BY, Kim KA, Kwon O, Kim SO, Kim MS, Kim BS et al. NF-kappaB inhibition radiosensitizes Ki-Ras-transformed cells to ionizing radiation. Carcinogenesis 2005; 26: 1395-1403.

10. Rojas A, Liu G, Coleman I, Nelson PS, Zhang M, Dash R et al. IL-6 promotes prostate tumorigenesis and progression through autocrine cross-activation of IGF-IR. Oncogene 2011; 30: 2345-2355

11. Mora LB, Buettner R, Seigne J, Diaz J, Ahmad N, Garcia R et al. Constitutive activation of Stat3 in human prostate tumors and cell lines: direct inhibition of Stat3 signaling induces apoptosis of prostate cancer cells. Cancer Res 2002; 62: 6659-6666.

12. Sun M, Liu C, Nadiminty N, Lou W, Zhu Y, Yang J et al. Inhibition of Stat3 activation by sanguinarine suppresses prostate cancer cell growth and invasion. Prostate 2012; 72 : 82-89.

13. Reddy KR, Guan Y, Qin G, Zhou Z, Jing N. Combined treatment targeting HIF-1alpha and Stat3 is a potent strategy for prostate cancer therapy. Prostate 2011; 71: 1796-1809.

14. Gao L, Zhang L, Hu J, Li F, Shao Y, Zhao D et al. Down-regulation of signal transducer and activator of transcription 3 expression using vector-based small interfering RNAs suppresses growth of human prostate tumor in vivo. Clin Cancer Res 2005; 11 : 6333-6341.

15. Ni Z, Lou W, Leman ES, Gao AC. Inhibition of constitutively activated Stat3 signaling pathway suppresses growth of prostate cancer cells. Cancer Res 2000; 60: 1225-1228.

16. Shin J, Lee HJ, Jung DB, Jung JH, Lee EO, Lee SG et al. Suppression of STAT3 and HIF-1 alpha mediates anti-angiogenic activity of betulinic acid in hypoxic PC-3 prostate cancer cells. PLoS One 2011; 6: e21492.

17. Lim S, Becker A, Zimmer A, Lu J, Buettner R, Kirfel J. SNAl1-mediated epithelialmesenchymal transition confers chemoresistance and cellular plasticity by regulating genes involved in cell death and stem cell maintenance. PLoS One 2013; 8: e66558.

18. Miyoshi A, Kitajima Y, Sumi K, Sato K, Hagiwara A, Koga Y et al. Snail and SIP1 increase cancer invasion by upregulating MMP family in hepatocellular carcinoma cells. $\mathrm{Br} \mathrm{J}$ Cancer 2004; 90: 1265-1273

19. Neal CL, McKeithen D, Odero-Marah VA. Snail negatively regulates cell adhesion to extracellular matrix and integrin expression via the MAPK pathway in prostate cancer cells. Cell Adh Migr 2011; 5: 249-257.

20. Haraguchi M, Okubo T, Miyashita Y, Miyamoto $Y$, Hayashi M, Crotti TN et al. Snail regulates cell-matrix adhesion by regulation of the expression of integrins and basement membrane proteins. J Biol Chem 2008; 283: 23514-23523.

21. Cano A, Perez-Moreno MA, Rodrigo I, Locascio A, Blanco MJ, del Barrio MG et al. The transcription factor snail controls epithelial-mesenchymal transitions by repressing E-cadherin expression. Nat Cell Biol 2000; 2: 76-83.

22. Batlle E, Sancho E, Franci C, Dominguez D, Monfar M, Baulida J et al. The transcription factor snail is a repressor of E-cadherin gene expression in epithelial tumour cells. Nat Cell Biol 2000; 2: 84-89.

23. Dontu G, Jackson KW, McNicholas E, Kawamura MJ, Abdallah WM, Wicha MS. Role of Notch signaling in cell-fate determination of human mammary stem/progenitor cells. Breast Cancer Res 2004; 6: R605-R615.

24. Fre S, Huyghe M, Mourikis P, Robine S, Louvard D, Artavanis-Tsakonas S. Notch signals control the fate of immature progenitor cells in the intestine. Nature 2005; 435 964-968.

25. Jarriault S, Brou C, Logeat F, Schroeter EH, Kopan R, Israel A. Signalling downstream of activated mammalian Notch. Nature 1995; 377: 355-358.

26. Maier MM, Gessler M. Comparative analysis of the human and mouse Hey1 promoter: Hey genes are new Notch target genes. Biochem Biophys Res Commun 2000; 275 652-660.

27. Barbera MJ, Puig I, Dominguez D, Julien-Grille S, Guaita-Esteruelas S, Peiro S et al. Regulation of Snail transcription during epithelial to mesenchymal transition of tumor cells Oncogene 2004; 23: 7345-7354.

28. Vega S, Morales AV, Ocana OH, Valdes F, Fabregat I, Nieto MA. Snail blocks the cell cycle and confers resistance to cell death. Genes Dev 2004; 18: 1131-1143.

29. Reginato MJ, Mills KR, Paulus JK, Lynch DK, Sgroi DC, Debnath J et al. Integrins and EGFR coordinately regulate the pro-apoptotic protein Bim to prevent anoikis. Nat Cell Biol 2003; 5: 733-740.

30. Marani M, Hancock D, Lopes R, Tenev T, Downward J, Lemoine NR. Role of Bim in the survival pathway induced by Raf in epithelial cells. Oncogene 2004; 23: 2431-2441.

31. Weston CR, Balmanno K, Chalmers C, Hadfield K, Molton SA, Ley R et al. Activation of ERK $1 / 2$ by deltaRaf-1:ER* represses Bim expression independently of the JNK or PI3K pathways. Oncogene 2003; 22: 1281-1293.

32. Ley R, Balmanno K, Hadfield K, Weston C, Cook SJ. Activation of the ERK1/2 signaling pathway promotes phosphorylation and proteasome-dependent degradation of the $\mathrm{BH}$ only protein, Bim. J Biol Chem 2003; 278: 18811-18816.

33. Kumar P, Benedict R, Urzua F, Fischbach C, Mooney D, Polverini P. Combination treatment significantly enhances the efficacy of antitumor therapy by preferentially targeting angiogenesis. Lab Invest 2005; 85: 756-767.
34. Imhof BA, Vollmers HP, Goodman SL, Birchmeier W. Cell-cell interaction and polarity of epithelial cells: specific perturbation using a monoclonal antibody. Cell 1983; 35(3 Pt 2): 667-675.

35. Behrens J, Mareel MM, Van Roy FM, Birchmeier W. Dissecting tumor cell invasion: epithelial cells acquire invasive properties after the loss of uvomorulin-mediated cell-cell adhesion. J Cell Biol 1989; 108: 2435-2447.

36. Singh A, Settleman J. EMT cancer stem cells and drug resistance: an emerging axis of evil in the war on cancer. Oncogene 2010; 29: 4741-4751.

37. Sarkar FH, Li Y, Wang Z, Kong D. Pancreatic cancer stem cells and EMT in drug resistance and metastasis. Minerva Chir 2009; 64: 489-500.

38. Kong D, Li Y, Wang Z, Sarkar FH. Cancer stem cells and epithelial-to-mesenchymal transition (EMT)-phenotypic cells: are they cousins or twins? Cancers 2011; 3: 716-729.

39. Izumiya M, Kabashima A, Higuchi $H$, Igarashi $T$, Sakai G, lizuka $H$ et al. Chemoresistance is associated with cancer stem cell-like properties and epithelial-to-mesenchymal transition in pancreatic cancer cells. Anticancer Res 2012; 32: 3847-3853.

40. Li H, Chen X, Calhoun-Davis T, Claypool K, Tang DG. PC3 human prostate carcinoma cell holoclones contain self-renewing tumor-initiating cells. Cancer Res 2008; 68: 1820-1825.

41. Andarawewa KL, Erickson AC, Chou WS, Costes SV, Gascard P, Mott JD et al. Ionizing radiation predisposes nonmalignant human mammary epithelial cells to undergo transforming growth factor beta induced epithelial to mesenchymal transition. Cancer Res 2007; 67: 8662-8670.

42. Jung JW, Hwang SY, Hwang JS, Oh ES, Park S, Han IO. Ionising radiation induces changes associated with epithelial-mesenchymal transdifferentiation and increased cell motility of A549 lung epithelial cells. Eur J Cancer 2007; 43: 1214-1224.

43. Gomez-Casal R, Bhattacharya C, Ganesh N, Bailey L, Basse P, Gibson M et al. Non-small cell lung cancer cells survived ionizing radiation treatment display cancer stem cell and epithelial-mesenchymal transition phenotypes. Mol Cancer 2013; 12: 94.

44. Kawamoto A, Yokoe T, Tanaka K, Saigusa S, Toiyama Y, Yasuda H et al. Radiation induces epithelial-mesenchymal transition in colorectal cancer cells. Oncol Rep 2012; 27: 51-57.

45. Thiery JP. Epithelial-mesenchymal transitions in tumour progression. Nat Rev Cancer 2002; 2: 442-454.

46. Thiery JP, Acloque $\mathrm{H}$, Huang RY, Nieto MA. Epithelial-mesenchymal transitions in development and disease. Cell 2009; 139: 871-890.

47. Escrivà M, Peiró S, Herranz N, Villagrasa P, Dave N, Montserrat-Sentís B et al. Repression of PTEN phosphatase by Snail 1 transcriptional factor during gamma radiation-induced apoptosis. Mol Cell Biol 2008; 28: 1528-1540.

48. Kurrey NK, Jalgaonkar SP, Joglekar AV, Ghanate AD, Chaskar PD, Doiphode RY et al. Snail and slug mediate radioresistance and chemoresistance by antagonizing p53mediated apoptosis and acquiring a stem-like phenotype in ovarian cancer cells. Stem Cells 2009; 27: 2059-2068.

49. Sun M, Guo X, Qian X, Wang H, Yang C, Brinkman KL et al. Activation of the ATM-Snail pathway promotes breast cancer metastasis. J Mol Cell Biol 2012; 4: 304-315.

50. Mani SA, Guo W, Liao MJ, Eaton EN, Ayyanan A, Zhou AY et al. The epithelialmesenchymal transition generates cells with properties of stem cells. Cell 2008; 133 : 704-715.

51. Scheel C, Eaton EN, Li SH, Chaffer CL, Reinhardt F, Kah KJ et al. Paracrine and autocrine signals induce and maintain mesenchymal and stem cell states in the breast. Cell 2011; 145: 926-940.

52. Zhu LF, Hu Y, Yang CC, Xu XH, Ning TY, Wang ZL et al. Snail overexpression induces an epithelial to mesenchymal transition and cancer stem cell-like properties in SCC9 cells. Lab Invest 2012; 92: 744-752.

53. Richardson GD, Robson CN, Lang SH, Neal DE, Maitland NJ, Collins AT. CD133, a novel marker for human prostatic epithelial stem cells. J Cell Sci 2004; 117(Pt 16): 3539-3545.

54. Takahashi K, Yamanaka S. Induction of pluripotent stem cells from mouse embryonic and adult fibroblast cultures by defined factors. Cell 2006; 126: 663-676.

55. Yu J, Vodyanik MA, Smuga-Otto K, Antosiewicz-Bourget J, Frane JL, Tian S et al Induced pluripotent stem cell lines derived from human somatic cells. Science 2007; 318: 1917-1920.

56. Lagadec C, Vlashi E, Alhiyari Y, Phillips TM, Dratver MB, Pajonk F. Radiation-induced notch signaling in breast cancer stem cells. Int J Radiat Oncol Biol Phys 2013; 87: 609-618.

57. Lagadec C, Vlashi E, Della Donna L, Dekmezian C, Pajonk F. Radiation-induced reprogramming of breast cancer cells. Stem Cells 2012; 30: 833-844.

58. Sahlgren C, Gustafsson MV, Jin S, Poellinger L, Lendahl U. Notch signaling mediates hypoxia-induced tumor cell migration and invasion. Proc Natl Acad Sci USA 2008; 105 : 6392-6397.

59. Woodward WA, Chen MS, Behbod F, Alfaro MP, Buchholz TA, Rosen JM. WNT/beta-catenin mediates radiation resistance of mouse mammary progenitor cells. Proc Natl Acad Sci USA 2007; 104: 618-623.

60. Phillips TM, McBride WH, Pajonk F. The response of CD24(-/low)/CD44 + breast cancer-initiating cells to radiation. J Natl Cancer Inst 2006; 98: 1777-1785.

61. Lagadec C, Vlashi E, Della Donna L, Meng Y, Dekmezian C, Kim K et al. Survival and self-renewing capacity of breast cancer initiating cells during fractionated radiation treatment. Breast Cancer Res 2010; 12: R13.

62. Evdokimova V, Tognon C, Ng T, Ruzanov P, Melnyk N, Fink D et al. Translational activation of snail1 and other developmentally regulated transcription factors by YB-1 promotes an epithelial-mesenchymal transition. Cancer Cell 2009; 15: 402-415. 
63. Tsai JH, Donaher JL, Murphy DA, Chau S, Yang J. Spatiotemporal regulation of epithelialmesenchymal transition is essential for squamous cell carcinoma metastasis. Cancer Cell 2012; 22: 725-736.

64. Yu M, Bardia A, Wittner BS, Stott SL, Smas ME, Ting DT et al. Circulating breast tumor cells exhibit dynamic changes in epithelial and mesenchymal composition. Science 2013; 339: 580-584.

65. Laberge RM, Awad P, Campisi J, Desprez PY. Epithelial-mesenchymal transition induced by senescent fibroblasts. Cancer Microenviron 2012; 5: 39-44.

66. Rodier F, Coppe JP, Patil CK, Hoeijmakers WA, Munoz DP, Raza SR et al. Persistent DNA damage signalling triggers senescence-associated inflammatory cytokine secretion. Nat Cell Biol 2009; 11: 973-979.
67. Wiederschain D, Wee S, Chen L, Loo A, Yang G, Huang A et al. Single-vector inducible lentiviral RNAi system for oncology target validation. Cell Cycle 2009; 8: 498-504.

68. Velimezi G, Liontos M, Vougas K, Roumeliotis T, Bartkova J, Sideridou M et al. Functional interplay between the DNA-damage-response kinase ATM and ARF tumour suppressor protein in human cancer. Nat Cell Biol 2013; 15: 967-977.

69. Vlasakova J, Novakova Z, Rossmeislova L, Kahle M, Hozak P, Hodny Z. Histone deacetylase inhibitors suppress IFN\{alpha\}-induced up-regulation of promyelocytic leukemia protein. Blood 2007; 109: 1373-1380.

70. Franken NAP, Rodermond HM, Stap J, Haveman J, van Bree C. Clonogenic assay of cells in vitro. Nat Protoc 2006; 1: 2315-2319.

Supplementary Information accompanies this paper on Cell Death and Differentiation website (http://www.nature.com/cdd) 